\author{
Universidade de São Paulo \\ Instituto de Física
}

\title{
Sinais experimentais de matéria escura supermassiva e fortemente interagente
}

\author{
Leandro José Beraldo e Silva
}

Orientadora: Prof ${ }^{a}$. Dra. Ivone F. M. Albuquerque

Dissertação de mestrado apresentada ao Instituto de Física para a obtenção

do título de Mestre em Ciências

Comissão Examinadora:

Profa $^{a}$. Dra. Ivone F. M. Albuquerque (IF-USP)

Prof. Dr. Ernesto Kemp (UNICAMP)

Prof. Dr. Laerte Sodré Jr. (IAG-USP)

São Paulo

2010 
Autorizo a reprodução e divulgação total e parcial deste trabalho, por qualquer meio convencional ou eletrônico, desde que citada a fonte.

\section{FICHA CATALOGRÁFICA \\ Preparada pelo Serviço de Biblioteca e Informação do Instituto de Física da Universidade de São Paulo}

Silva, Leandro José Beraldo e

Sinais experimentais de matéria escura supermassiva e fortemente interagente. São Paulo, 2010.

Dissertação (Mestrado) - Universidade de São Paulo.

Instituto de Física - Depto. de Física Experimental

Orientador: Profa. Dra. Ivone Freire da Mota Albuquerque

Área de Concentração: Física

Unitermos: 1. Matéria escura; 2. Raios cósmicos; 3. Astropartículas; 4. Extensões do modelo padrão de partículas; 5. Telescópios de neutrinos. 


\section{Agradecimentos}

Aos meus pais, Edina e Lennimar, pelo apoio incondicional, pelos esforços realizados na minha educação, desde a infância até os dias de hoje, e pela compreensão de todos os momentos em que estive ausente.

Aos meus irmãos, Heidi (Tata) e Maurício, pela confiança depositada em mim, e pelo afeto gigantesco que sempre recebi ao chegar em casa e ficar cercado de crianças (Má, Helô e Gu).

À Carol, pelo amor e afeto, e pela imensa paciência no período (crítico) de finalização deste projeto.

A todos os amigos da "Turma da Física" — ingressantes, ou não, em 2003 - com quem vivi, e ainda vivo, momentos muito felizes.

À Adriana e à Maria Paula, pela recepção e hospedagem tão solidárias no começo da graduação, e pelas conversas sempre instrutivas e divertidas. Ao Boris por ter proporcionado este encontro e pela longa amizade e companheirismo.

Ao Leopoldo, por todas as conversas e pelo abrigo na Afonso Vaz, de onde só tenho boas lembranças, divididas com os grandes amigos que conheci por lá: Mafê, Lucas, Carol, Tati, Moisés, Marta e Edimar.

Aos amigos do "Clube do Café" e do LAL em geral: Leandro Mariano (LM) - com quem dividi sala e tive sempre ótimas conversas - Raphael (Shock), Viktor, Felipe, Felisberto, Nataly — pelos cafés sempre bem-humorados —, Sérgio, Diogo, Jairo pelas ajudas computacionais - e Priscila - por me passar as aulas particulares que me salvaram (\$) no período em que estive sem bolsa.

Às funcionárias do Restaurante da Física, em especial à D. Clara, à Mônica e à D. Vera.

A todos os professores que contribuíram para a minha formação, desde o ensino fundamental até a pós-graduação.

Ao professor Laerte Sodré Jr., que me orientou muito atenciosamente durante o Trabalho de Graduação no IAG.

À professora Ivone Albuquerque, por toda a ajuda, atenção, estímulo e paciência, desde a Iniciação Científica até a conclusão desta dissertação. Nada que disser expressará suficientemente minha gratidão. A ela deixo meus agradecimentos especiais.

Por fim, agradeço à Fapesp e ao $\mathbf{C N P q}$ pelo financiamento e ao Laboratório do Acelerador Linear (LAL) do Departamento de Física Experimental pela infraestrutura disponibilizada durante a realização deste projeto. 



\section{O ENIGMA}

As pedras caminhavam pela estrada. Eis que uma forma obscura lhes barra o caminho. Elas se interrogam, e à sua experiência mais particular. Conheciam outras formas deambulantes, e o perigo de cada objeto em circulação na terra. Aquele, todavia, em nada se assemelha às imagens trituradas pela experiência, prisioneiras do hábito ou domadas pelo instinto imemorial das pedras. As pedras detêm-se. No esforço de compreender, chegam a imobilizar-se de todo. E na contenção desse instante, fixam-se as pedras - para sempre - no chão, compondo montanhas colossais, ou simples e estupefatos e pobres seixos desgarrados.

Mas a coisa sombria - desmesurada, por sua vez - aí está, à maneira dos enigmas que zombam da tentativa de interpretação. É mal de enigmas não se decifrarem a si próprios. Carecem de argúcia alheia, que os liberte de sua confusão amaldiçoada. E repelem-na ao mesmo tempo, tal é a condição dos enigmas. Esse travou o avanço das pedras, rebanho desprevenido, e amanhã fixará por igual as árvores, enquanto não chega o dia dos ventos, e o dos pássaros, e o do ar pululante de insetos e vibrações, e o de toda vida, e o da mesma capacidade universal de se corresponder e se completar, que sobrevive à consciência. O enigma tende a paralisar o mundo.

Talvez que a enorme Coisa sofra na intimidade de suas fibras, mas não se compadece nem de si nem daqueles que reduz à congelada expectação.

Ai! de que serve a inteligência - lastimam-se as pedras. Nós éramos inteligentes; contudo, pensar a ameaça não é removê-la; é criá-la.

Ai! de que serve a sensibilidade - choram as pedras. Nós éramos sensiveis, e o dom de misericórdia se volta contra nós, quando contávamos aplicá-lo a espécies menos favorecidas.

Anoitece, e o luar, modulado de dolentes canções que preexistem aos instrumentos de música, espalha no côncavo, já pleno de serras abruptas e de ignoradas jazidas, melancólica moleza.

Mas a Coisa interceptante não se resolve. Barra o caminho e medita, obscura.

C. D. de Andrade, em Novos poemas. 


\section{Resumo}

Há várias evidências experimentais da existência de matéria escura no universo. Apesar destas evidências, pouco se sabe sobre sua constituição, sabendo-se apenas que interage gravitacionalmente, mas não eletromagneticamente.

Neste projeto, investigamos a possibilidade da matéria escura ser composta por partículas supermassivas e fortemente interagentes (Simpzillas). Para isto determinamos o sinal que deve ser deixado no telescópio IceCube por neutrinos resultantes de aniquilações de matéria escura no Sol. Após determinarmos o espectro de neutrinos no centro do Sol, simulamos sua propagação até a superfície, depois até a Terra e através da Terra até o detector. Comparamos então estes resultados com os fornecidos pelo IceCube. Esta comparação permite testar uma região do espaço de fase massa versus seção de choque previamente não-excluída por outros tipos de experiência que não telescópios de neutrinos.

Como resultado, concluímos que partículas supermassivas e fortemente interagentes não podem constituir a matéria escura. 


\section{Abstract}

There are many experimental evidences for the existence of dark matter in the universe. Despite these evidences, there is no knowledge about its constitution other than the fact that it interacts gravitationally but not electromagnetically.

In this project, we investigate the possibility that dark matter is composed of strongly interacting massive particles (Simpzillas). We determine the expected signal in the IceCube telescope from Simpzilla annihilation in the center of the Sun.

We first determine the neutrino spectrum in the core of the Sun. We then simulate its propagation through both the Sun and Earth, and finally the rate of neutrinos at the detector. A comparison of these results to the ones published by the IceCube collaboration covers a large region of the yet not excluded regions of the mass versus cross-section phase space.

As a result, the possibility of Simpzillas composing the dark matter is ruled out. 


\section{Sumário}

Sumário $\quad$ ix

1 Introdução 1

1.1 Evidências experimentais . . . . . . . . . . . . . . . . 3

1.1.1 Massa dos aglomerados . . . . . . . . . . . . . . 3

1.1.2 Curvas de rotação . . . . . . . . . . . . . . . . . 4

1.1.3 Lentes gravitacionais . . . . . . . . . . . . . . . 6

1.1.4 "Bullet Cluster" . . . . . . . . . . . . . . . . . . 6

1.1.5 Nucleossíntese primordial . . . . . . . . . . . . . . 8

1.1.6 Formação de estruturas . . . . . . . . . . . . . . . . . . . 8

2 Partículas candidatas a matéria escura $\quad 11$

2.1 Candidatos do Modelo Padrão (MP) . . . . . . . . . . . . . . . . . . 11

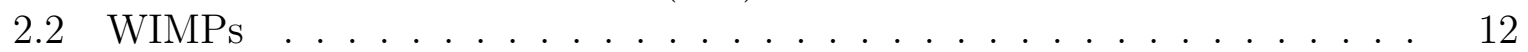

2.3 Partículas supermassivas . . . . . . . . . . . . . . . . . 14

2.4 Partículas supermassivas e $\quad \ldots \ldots \ldots$. . . . . . . . . . . . 16

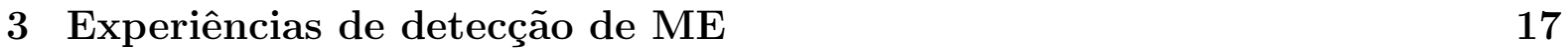

3.1 Detecção direta . . . . . . . . . . . . . . . . . . . . . . 17

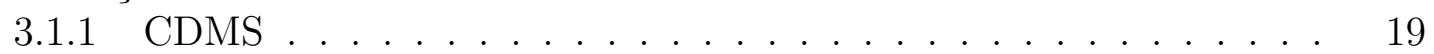

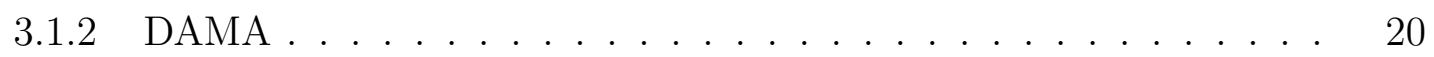

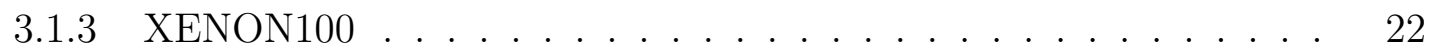

3.2 Detecção Indireta . . . . . . . . . . . . . . . . . . . . . . . . 22

3.2 .1 O IceCube . . . . . . . . . . . . . . . . . . 24

4 Espectro de neutrinos resultantes das aniquilações de $\chi$ 's no Sol $\quad 27$

4.1 Aniquilações no núcleo do Sol . . . . . . . . . . . . . . . . . . . . . . . 27

4.2 A taxa de captura . . . . . . . . . . . . . . . . . . . 29

4.3 O espectro de neutrinos no núcleo do Sol . . . . . . . . . . . . . . 32

4.4 Propagação dos neutrinos . . . . . . . . . . . . . . . . 34

4.4 .1 Espectro de $\nu_{\mu}$ 's . . . . . . . . . . . . . 36

5 Comparação com os dados e conclusões $\quad 39$

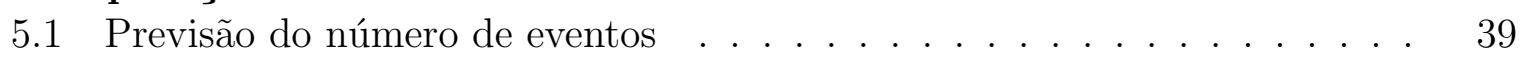

5.2 Comparação com os dados do IceCube . . . . . . . . . . . . . . . . . 40

5.3 Discussão dos resultados . . . . . . . . . . . . . . . . . . . . . 42 
5.3 .1 Incerteza na densidade local . . . . . . . . . . . . . . . . . . . . 42

5.3 .2 Incerteza na velocidade . . . . . . . . . . . . . . . . . . . . . 43

5.3.3 Velocidade de escape da Galáxia . . . . . . . . . . . . . . . 45

5.4 Conclusões . . . . . . . . . . . . . . . . . . . . 46

A Curvas de Rotação em detalhes $\quad 49$

$\begin{array}{ll}\text { Referências Bibliográficas } & 51\end{array}$ 


\section{Capítulo 1}

\section{Introdução}

Esta dissertação analisa aspectos do enigma da matéria escura, que está associada à massa faltante em objetos astrofísicos na escala de pequenas galáxias até grandes aglomerados de galáxias. Este enigma surge devido a uma incompatibilidade entre a quantidade de matéria inferida a partir de observações com telescópios (radiação eletromagnética) e aquela determinada através de efeitos gravitacionais, sendo esta sempre maior.

Há muitos resultados experimentais que evidenciam o problema da massa faltante no universo. As principais evidências dessa discrepância são obtidas por meio de medidas de massas de galáxias em aglomerados a partir de sua dispersão de velocidades, as curvas de rotação, a determinação das massas de aglomerados usando lentes gravitacionais e/ou medidas de Raios-X, e os "Bullet Clusters".

Existem diferentes propostas para solucionar este problema, entre elas: alterar a lei da gravitação, cujo modelo mais popular é o MOND (Modified Newtonian Dynamics), ou atribuir essa massa faltante a algum tipo de matéria que, apesar de sofrer ação da força gravitacional, não interage eletromagneticamente e por isso é denominada matéria escura (ME). Nossa investigação se enquadra neste segundo tipo de proposta, que é o único que dá solução a todos os problemas relacionados à massa faltante.

De acordo com as medidas mais recentes [1], a ME representa cerca de 22, 2\% $\pm 2,6 \%$ do conteúdo energético do universo. O restante é composto por matéria comum (constituída de partículas conhecidas, principalmente prótons e nêutrons e por isso aqui chamada de matéria bariônica), que contribui com 4,49\% $\pm 0,28 \%$ e energia escura, a que se atribui a aceleração do universo, que representa $73,4 \% \pm 2,9 \%$ de seu conteúdo energético total.

Apesar de haver muitas evidências experimentais da existência da ME, pouco ou nada se sabe acerca da sua natureza, ou seja, de que tipo de partícula ela é constituída, qual sua massa e através de que forças ela interage com as outras partículas. Sabe-se, porém, como discutiremos mais adiante, que ela não é constituída por matéria conhecida.

Se o halo galático (distribuição esferoidal de massa ao redor do plano da Via Láctea) é 
composto por ME (fraca ou fortemente interagente), suas partículas constituintes devem atravessar o Sistema Solar e ser aí capturadas. Neste caso, elas se concentram no núcleo do Sol e passam a se aniquilar, gerando um espectro de partículas conhecidas, entre as quais os neutrinos. A detecção destes neutrinos permite testar indiretamente a composição da ME.

Este trabalho se insere na investigação dos possíveis constituintes da ME e na possibilidade dela ser constituída de partículas supermassivas e fortemente interagentes. Nosso objetivo é testar partículas com estas características, através da detecção de neutrinos produzidos a partir de sua aniquilação no centro do Sol. Testes deste tipo de partículas já foram realizados de diversas formas. A Figura 1.1 representa o espaço de fase massa versus seção de choque testado em análises anteriores à descrita aqui, as quais foram realizadas por experiências de detecção direta de ME, medidas em minas e no espaço e também através de medidas do calor da Terra [4-7]. Apesar de grande parte deste espaço de fase já estar descartado, nesta dissertação descreveremos o teste das lacunas desta zona de exclusão de parâmetros.

Para testar a região permitida para a existência de candidatos massivos que interagem fortemente (triângulos em branco na Figura 1.1), determinamos, através de simulações Monte-Carlo, o sinal que os neutrinos gerados nas aniquilações no núcleo solar devem deixar em telescópios do tipo do IceCube [2] e em seguida comparamos os resultados deste experimento com o previsto por nossas simulações.

O texto está organizado da seguinte forma: neste capítulo descrevemos os resultados experimentais que evidenciam o problema da massa faltante no universo, dando ênfase ao fato de que estes, apesar de constituírem medidas independentes, implicam aproximadamente na mesma quantidade de ME.

O capítulo seguinte apresenta algumas partículas candidatas a compor a ME, passando por tentativas do Modelo Padrão de partículas (MP), depois pelos Weakly Interacting Massive Particles (WIMPs) e finalmente por partículas supermassivas fortemente interagentes.

No terceiro capítulo explicamos o funcionamento de experiências de detecção de ME, detalhando o processo de detecção indireta utilizando-se um telescópio de neutrinos, tendo em mente o funcionamento do IceCube.

$\mathrm{Na}$ capítulo 4 são feitas as deduções das expressões relevantes ao cálculo do sinal esperado. Também explicitamos a simulação Monte-Carlo que fizemos, com a ajuda do software WIMPSIM [8], a fim de prever o espectro de neutrinos que devem chegar ao detector.

Por fim, no capítulo 5 determinamos os resultados previstos levando em conta as características do IceCube. Comparamos então nossas previsões com os dados publicados 


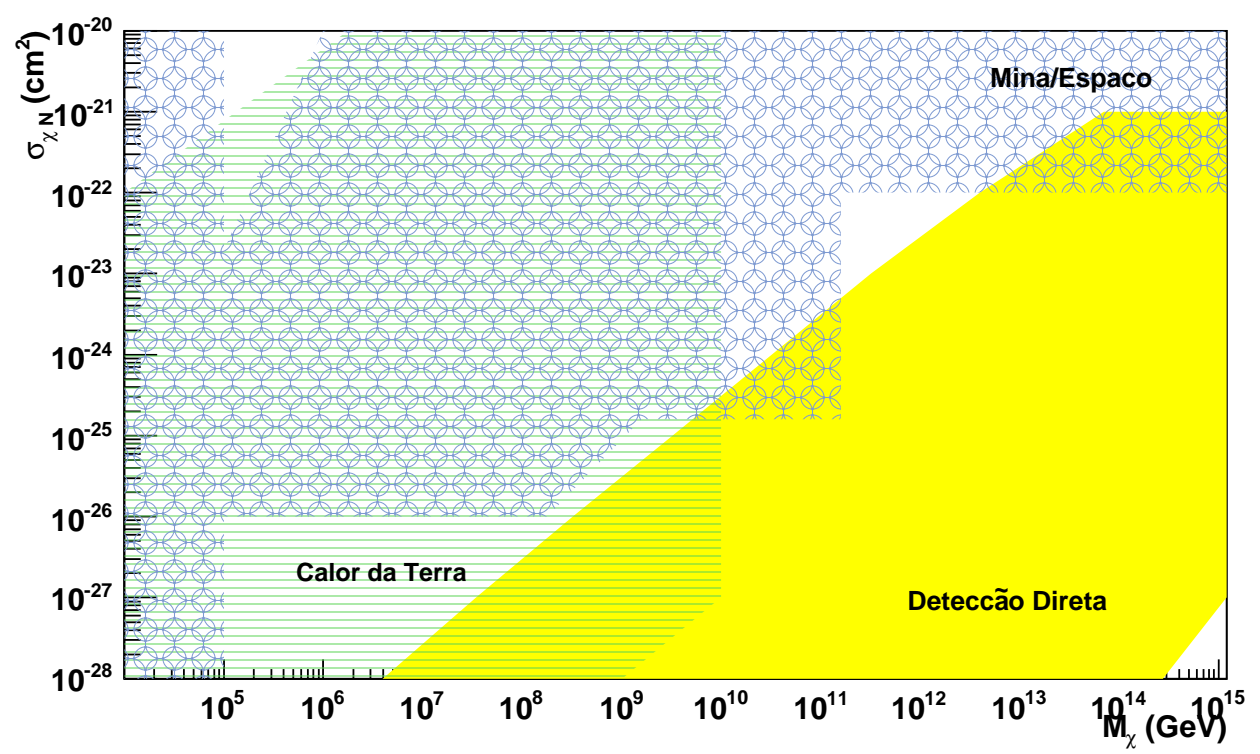

Figura 1.1: Zona de exclusão (nível de confiança de 90\%) para partículas supermassivas fortemente interagentes antes da análise descrita nesta dissertação. A região amarela foi obtida com experiências de detecção direta de ME [4]. A região verde através da medida do calor da Terra [5] e a azul através de medidas subterrâneas e no espaço [6,7].

por essa experiência, testando desta forma o espaço de fase massa versus seção de choque ainda permitido para a existência destas partículas. Por fim, apresentamos nossas conclusões acerca da possibilidade de existência dessas partículas supermassivas e fortemente interagentes, analisando também o impacto das incertezas de alguns parâmetros astrofísicos sobre os resultados.

\subsection{Evidências experimentais}

\subsubsection{Massa dos aglomerados}

A primeira evidência do problema da massa faltante foi percebida por Fritz Zwicky, na década de 1930, ao estudar o movimento das galáxias no aglomerado de Coma [9,10]. Depois de catalogadas as velocidades de todas aquelas galáxias, Zwicky calculou sua média e desvio-padrão, associando este último à velocidade média ao redor do centro de massa do aglomerado. Aplicou então o Teorema do Virial, que diz que, num sistema em equilíbrio, energia potencial e cinética podem ser relacionadas como $2\langle T\rangle+\langle V\rangle=0$, e com isso foi capaz de obter uma estimativa para a massa total do aglomerado e consequentemente para a massa média das galáxias ali presentes. Comparando esses resultados com as es- 
timativas de massas e luminosidades dos sistemas estelares próximos ao Sistema Solar, percebeu que a razão massa-luminosidade para as galáxias no aglomerado era mais de 100 vezes maior que para os aglomerados de estrelas próximos, atribuindo essa diferença à presença de algum tipo de matéria que não emitia, absorvia ou espalhava a luz e que por isso foi chamada por ele de "matéria escura". Poucos anos depois, a mesma constatação foi feita por Sinclair Smith [11] estudando o aglomerado de Virgo. Algumas décadas mais tarde verificou-se que a conclusão destes autores estava correta, apesar de terem utilizado o valor da constante de Hubble aceito naquela época (diferente do valor atual), o que altera a razão massa-luminosidade.

\subsubsection{Curvas de rotação}

Ainda no fim da década de 1930, teve início o estudo do movimento de rotação das regiões externas de galáxias espirais próximas, como a galáxia de Andrômeda (M31) e do Triângulo (M33), através das curvas de rotação. Essas curvas são representadas pela velocidade de rotação como função da distância ao centro da galáxia, como mostra a Figura 1.2. Embora as primeiras curvas rotacionais já deixassem clara a incompatibilidade das velocidades de rotação nas regiões externas com a distribuição de massa observada, a associação do problema de massa faltante nessas curvas com a ME nos aglomerados só foi feita a partir da década de 1970. Esta incompatibilidade fica clara na Figura 1.2, onde se nota a predominância da contribuição do halo de ME nas regiões externas da galáxia M33.

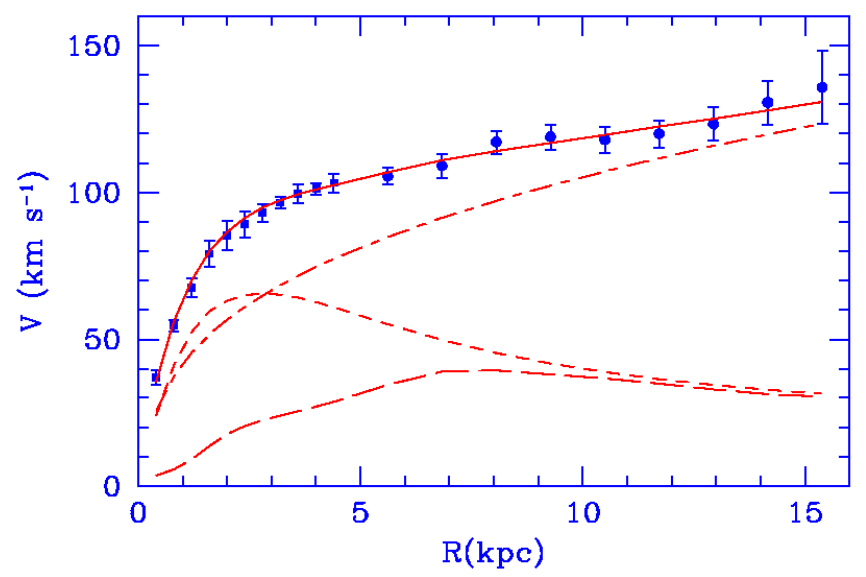

Figura 1.2: Curva de rotação da galáxia M33 - extraído de [12]. São mostradas a curva ajustada (contínua), as contribuições do halo de ME (linha tracejada-pontilhada), do disco estelar (linha de tracejado pequeno) e do gás do meio interestelar (linha de tracejado grande). 
As velocidades de rotação das galáxias espirais são obtidas estudando-se o movimento do hidrogênio neutro em seus planos, o que é feito com o auxílio da linha de $21 \mathrm{~cm}$, que fornece a velocidade da fonte através do efeito Doppler. Essa linha equivale à radiação emitida pelo hidrogênio atômico devido à transição entre estados de diferentes orientações relativas do spin do próton e do elétron (estrutura hiper-fina), cujo comprimento de onda mede $21 \mathrm{~cm}$. Essa transição é muito rara, o que torna essa medida, em laboratório, muito difícil. Apesar disso, a enorme quantidade de hidrogênio neutro no plano das galáxias espirais faz com que essa linha seja facilmente detectável. Também apresenta a vantagem de estar na faixa do radio no espectro eletromagnético, e assim quase não sofre extinção no meio interestelar, o que permite que a radiação viaje longas distâncias sem ser absorvida.

Além das velocidades de rotação, a linha de $21 \mathrm{~cm}$ permite determinar a distribuição de massa do hidrogênio neutro no plano das galáxias, o que possibilita, por sua vez, obter sua contribuição à velocidade de rotação (curva referente ao gás do meio interestelar na Figura 1.2). A distribuição de massa das estrelas (disco estelar) é determinada através das medidas da luminosidade em alguma banda do espectro visível.

A relação entre as curvas de rotação e a ME pode ser descrita da seguinte forma: dado que, numa distribuição de massa esfericamente simétrica, a atração gravitacional que uma partícula sofre depende apenas da massa interna à sua trajetória $(M(r))$, sua velocidade $v(r)$ de rotação como função da distância ao centro pode ser obtida igualandose a resultante centrípeta à força gravitacional:

$$
m \frac{v^{2}}{r}=\frac{G m M(r)}{r^{2}} \Rightarrow v(r)=\sqrt{\frac{G M(r)}{r}} .
$$

Como a massa interna depende de $r$, não é possível determinar a priori a dependência em $r$ da velocidade de rotação para as partes internas do disco da galáxia, a menos que se assuma conhecida a densidade de massa. Entretanto, nas partes mais externas do plano, ao variar a distância, a massa interna permanece aproximadamente constante, o que indica que nessa região deveríamos ter $v \propto r^{-\frac{1}{2}}$, o que não é observado na figura 1.2. No apêndice A, há uma análise mais detalhada dessa questão.

Em todas as curvas de rotação obtidas até o momento, a velocidade de rotação continua crescendo, ou pelo menos permanece constante, para grandes distâncias do centro. Isso indica a presença de grande quantidade de matéria nas partes mais externas, contrariamente à distribuição de massa medida em $21 \mathrm{~cm}$ e no visível, o que implica que esse excesso de matéria não interage eletromagneticamente, devendo ser atribuído à presença de ME. Em todas as curvas de rotação, a quantidade implicada de ME é cerca de 10 vezes maior que a de matéria bariônica [13]. 


\subsubsection{Lentes gravitacionais}

Hoje em dia as massas de aglomerados de galáxias podem também ser medidas através do efeito de lente gravitacional que produzem sobre as imagens das galáxias de fundo: um raio de luz vindo de uma fonte puntiforme, ao atravessar uma região de campo gravitacional intenso, sofre uma deflexão, e a imagem produzida aparece deslocada da posição verdadeira. No caso de uma fonte extensa, como é o caso de uma galáxia, aparecem efeitos mais complexos como a alteração do brilho superficial da imagem, criação de imagens múltiplas associadas ao mesmo objeto e alteração da forma das imagens. Por exemplo, pode-se mostrar que o efeito de lente gravitacional sobre a luz proveniente de objetos circulares forma imagens elípticas que tendem a se alinhar tangencialmente às equipotenciais do campo gravitacional. A análise da intensidade destes efeitos fornece informações sobre a massa total e a densidade superficial de massa de aglomerados. A comparação destas informações com aquelas inferidas das medidas de Raios-X emitidos pelo gás quente entre as galáxias de um aglomerado implica na presença de aproximadamente a mesma quantidade de ME que a obtida pelos outros métodos: de 5 a 10 vezes mais ME que matéria bariônica $[14,15]$.

\subsection{4 "Bullet Cluster"}

"Bullet Cluster" é o nome dado a um encontro entre aglomerados de galáxias em alta velocidade [16]. A Figura 1.3 mostra um destes encontros.

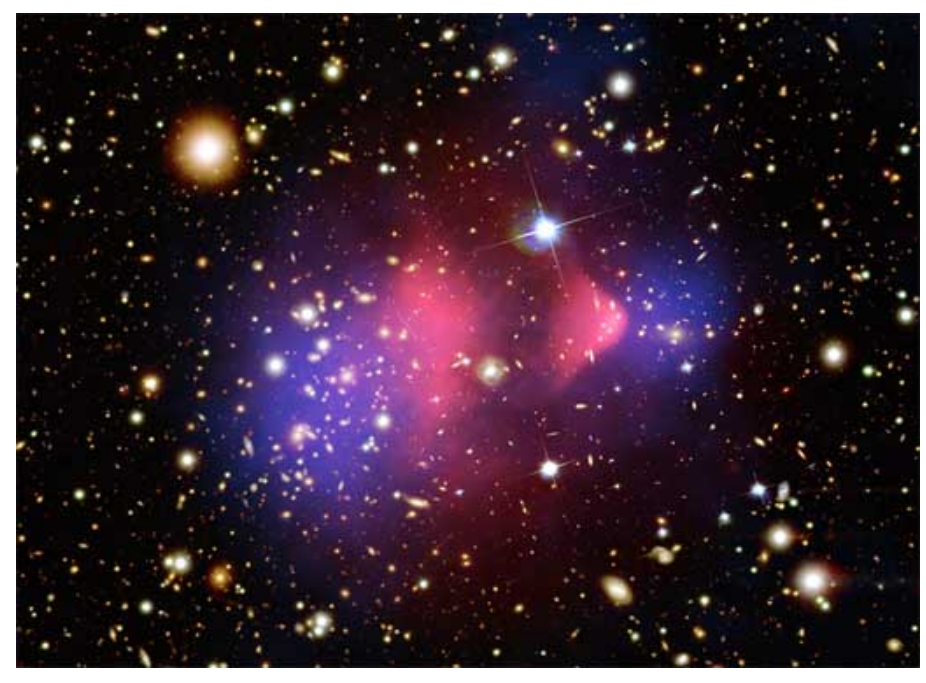

Figura 1.3: Encontro de dois aglomerados (1E0657-558) (extraído de [16]). A região vermelha central representa matéria comum (bariônica), na forma de gás quente. As regiões azuis externas representam a matéria escura. 
Nos aglomerados em geral, ME e matéria bariônica estão misturadas. As medidas indicam que a maior parte $(\sim 90 \%)$ da massa bariônica está na forma de gás quente (da ordem de milhões de Kelvins) entre as galáxias e cerca de 10\% está dentro das galáxias (estrelas e gás). As galáxias são consideradas objetos "não-colisionais", no sentido de que, em um encontro de aglomerados, as galáxias não se chocam, havendo apenas interações à distância. O gás entre as galáxias de um aglomerado, entretanto, interage bastante, devendo ser freado durante o encontro. Portanto, depois que dois aglomerados se encontram, espera-se que as galáxias passem adiante e que o gás fique retido na região interna do encontro. E como o gás representa $90 \%$ da matéria bariônica, os picos de densidade também devem ficar nessa região.

O "Bullet Cluster" mostrado foi estudado por meio de dois tipos de observação: com o satélite Chandra foi medida a emissão de Raios-X da região [17]. Com o Hubble Space Telescope foi estudado o efeito de lente gravitacional produzido por esses aglomerados sobre as imagens das galáxias de fundo, através da análise estatística de suas elipticidades. A primeira medida, com Raios-X, fornece um mapeamento da distribuição de massa da matéria bariônica. A segunda, com o uso do efeito de lente, determina a distribuição da massa total, independente de sua natureza, dos dois aglomerados.
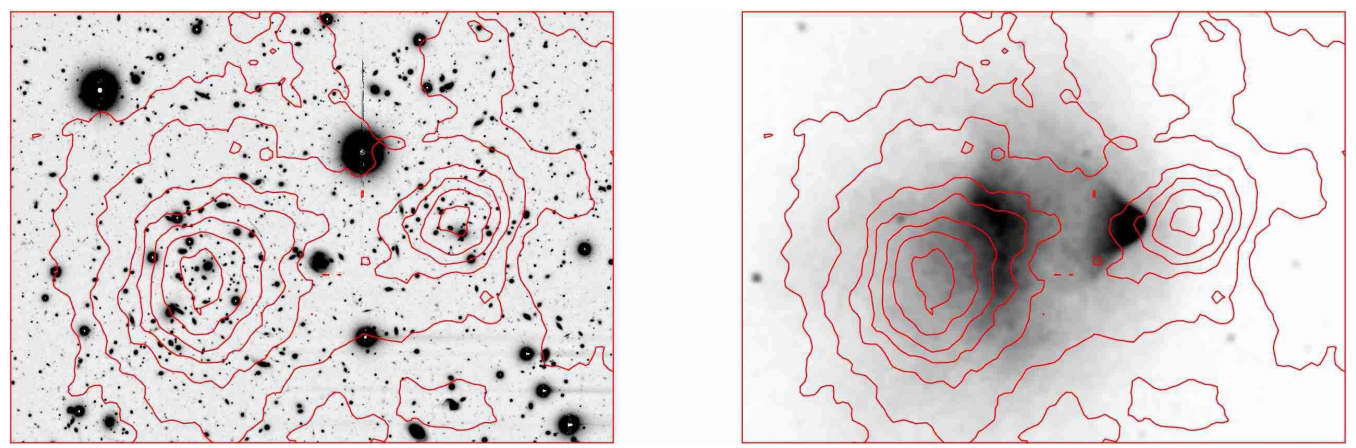

Figura 1.4: Mostra as curvas de nível para a densidade superficial de massa (linhas contínuas). No painel à esquerda os pontos são imagens das galáxias na banda $\mathrm{R}$. $\mathrm{O}$ painel da direita mostra a emissão em Raios-X. Extraído de [16].

O que se constatou com esses dois tipos de observação (Figura 1.4) foi que os picos de densidade não estão nas regiões internas do encontro, mas nas externas, em coincidência com as posições das galáxias, embora elas representem apenas $10 \%$ da massa bariônica. Isso pode ser explicado com a presença de uma grande quantidade ME nos aglomerados: por não interagir eletromagneticamente, suas partículas constituintes também devem ser não-colisionais e, depois do encontro, passar adiante como as galáxias, o que faz com que os picos de densidade fiquem nessas regiões. Isso cria sérias dificuldades para algumas tentativas de explicação do problema da massa faltante que tentam prescindir da hipótese 
da ME para resolvê-lo através de alterações na força gravitacional, como por exemplo o MOND.

\subsubsection{Nucleossíntese primordial}

Outra evidência experimental da existência de ME são as medidas associadas à Nucleosíntese Primordial. Este processo, como o nome já diz, refere-se à criação dos primeiros núcleos atômicos no início do universo. Logo depois do Big Bang, o universo era muito quente, de modo que os fótons tinham altíssimas energias, suficientes para não permitir que os prótons, através da interação forte, permanecessem ligados aos nêutrons formando núcleos. Conforme o universo se expande, a temperatura vai diminuindo, até que os fótons não têm energia suficiente para "quebrar" os núcleos, que passam a se formar e posteriormente dão origem aos elementos leves (H, D, ${ }^{4} \mathrm{He},{ }^{3} \mathrm{He}$ e $\left.{ }^{7} \mathrm{Li}\right)$. Esta produção continua até esgotar o número de nêutrons disponíveis.

A previsão da abundância primordial de cada um dos elementos acima envolve reações muito bem conhecidas experimentalmente e por isso essa previsão é bastante confiável. Para verificá-la experimentalmente, medem-se as abundâncias relativas destes elementos em objetos astrofísicos nos quais a produção de elementos por estrelas tenha sido pequena ou nula, por exemplo grandes nuvens gasosas com densidade insuficiente para formar estrelas.

A determinação da abundância primordial destes elementos impõe um forte vínculo sobre a quantidade total de matéria bariônica no universo. Os resultados destas medidas estão em ótimo acordo com as previsões teóricas [18] e indicam que apenas 4,49\% do conteúdo energético total do universo é constituído de bárions, sendo que $26,6 \%$ é a contribuição total de matéria [1]. Portanto essas medidas indicam que cerca de $22 \%$ do universo deve necessariamente ser composto de matéria não-bariônica, ou seja, matéria escura.

\subsubsection{Formação de estruturas}

As grandes estruturas do universo (galáxias e aglomerados de galáxias) se formaram a partir de pequenas inomogeneidades em sua densidade de matéria. Esses "caroços" de matéria começam a crescer devido à atração gravitacional das partículas e vão formando regiões com grande densidade central. Devido à interação eletromagnética, há uma pressão de radiação que contrabalanceia esse colapso, tornando-o mais lento. $\mathrm{Na}$ ausência de ME esse processo duraria muito tempo, muito mais do que indicam as observações das primeiras estruturas formadas. A presença de matéria escura, entretanto, faz com que esse colapso seja mais rápido pois suas partículas não sofrem ação da pressão 
de radiação por não interagir eletromagneticamente, formando regiões mais densas que por sua vez atraem mais intensamente matéria escura e bariônica. Esses resultados são confirmados através de simulações que levam em conta a presença de ME nos aglomerados em quantidades próximas àquelas estimadas através das observações descritas anteriormente [19]. 


\section{Capítulo 2}

\section{Partículas candidatas a matéria}

\section{escura}

Apresentadas as evidências experimentais da existência de ME, podemos nos perguntar sobre sua constituição. Neste capítulo apresentamos alguns modelos de partículas candidatas à ME, em especial os WIMPs e partículas supermassivas.

\subsection{Candidatos do Modelo Padrão (MP)}

Desde as primeiras evidências experimentais da existência de ME, cogitou-se a possibilidade dela ser constituída por objetos como planetas gigantes, anãs-marrons, anãsbrancas e estrelas de nêutrons, que são massivos mas não brilham como estrelas. Estes objetos são chamados conjuntamente de MAssive Compact Halo Objects (MACHOs). Buscas por MACHOs foram realizadas por várias experiências [20]. Resultados recentes indicam, porém, que o halo galático não pode ser composto apenas por MACHOs, e que estes representam no máximo apenas uma pequena parte de sua massa total [21].

Também foi considerada a possibilidade da ME ser constituída por neutrinos, e aqui precisamos fazer uma distinção entre os modelos de Matéria Escura Fria e Matéria Escura Quente. Estes termos referem-se à energia cinética média das partículas constituintes da ME na época da formação de estruturas. A ME Fria é constituída de partículas que tinham movimento não-relativístico nessa época, enquanto as partículas constituintes da ME Quente tinham movimento relativístico, estando os neutrinos nesta categoria. Simulações da formação de estruturas indicam que partículas de ME com movimento relativístico não poderiam aglutinar-se e com isso acentuar os "caroços" necessários à formação de estruturas. Por isso a possibilidade dos neutrinos responderem à questão da massa faltante nos halos também foi descartada, assim como os modelos de Matéria Escura Quente em geral. 
Assim, esgotam-se as possibilidades da ME ser composta por partículas já conhecidas, e entram em cena partículas previstas por modelos de extensão do MP. Ao mesmo tempo, estas extensões são necessárias devido a problemas que surgem com o MP em altas energias (a partir de centenas de TeV). Esses modelos prevêem a existência de novas partículas que podem naturalmente dar conta da questão da ME. Alguns candidatos são os axions e os WIMPs (Weakly Interacting Massive Particles), e também partículas massivas que interagem fortemente. Aqui descreveremos estes dois últimos.

\subsection{WIMPs}

Os WIMPs, como o nome já diz, constituem uma classe de candidatos massivos e com seções de choque de interação com outras partículas da ordem das interações fracas. Uma hipótese comumente adotada é que estas partículas tenham compartilhado do equilíbrio térmico com os demais tipos de partículas que compunham o plasma primordial: elétrons, pósitrons, neutrinos e bárions, todos eles acoplados, direta ou indiretamente, aos fótons. Para partículas sem interação eletromagnética, como os neutrinos e WIMPs, este "acoplamento" depende de uma reação intermediária: no caso dos neutrinos, $\nu \bar{\nu} \leftrightarrow e \bar{e} \leftrightarrow \gamma$.

No caso dos WIMPs $(\chi)$, a reação que mantém o equilíbrio com o plasma é $\chi \bar{\chi} \leftrightarrow$ $l \bar{l} \leftrightarrow \gamma$, em que $l$ representa de modo geral as partículas resultantes das suas aniquilações. A abundância (densidade numérica $n$ ) de $\chi$ 's é governada então por três fatores: a taxa de expansão do universo, a taxa de aniquilação de $\chi$ 's e sua taxa de produção. Portanto, para que este equilíbrio com o plasma se mantenha, é necessário que:

- As aniquilações dos $\chi$ 's ocorram a uma taxa suficientemente grande comparada à taxa de expansão do universo;

- As partículas $l$, mais leves que os $\chi$ 's, tenham energia suficiente para produzi-los, na reação inversa, e interajam (eletromagneticamente) com os fótons.

Nestas circunstâncias, a abundância dos $\chi$ 's, usando condições periódicas de contorno e as hipóteses de isotropia e homogeneidade espaciais, pode ser obtida como

$$
n_{e q}=g \frac{1}{(2 \pi \hbar)^{3}} \int \frac{4 \pi p^{2} d p}{e^{\frac{E}{k T}} \pm 1},
$$

onde $g$ é o parâmetro de degenerescência, $\vec{p}$ é o momento, $E$ é a energia dos WIMPs de massa $M_{\chi}, T$ é a temperatura compartilhada com o plasma (associada à energia dos fótons) e o sinal \pm refere-se a férmions e bósons respectivamente.

Esta abundância pode ser calculada em dois regimes extremos. Enquanto a temperatura é muito alta, os $\chi$ 's são criados com altas energias e têm movimentos relativísticos, 
o que nos permite fazer $E \approx p c$, que leva a

$$
n_{e q}=g \frac{4 \pi}{(2 \pi \hbar)^{3}}\left(\frac{k T}{c}\right)^{3} \int_{0}^{\infty} \frac{x^{2} d x}{e^{x} \pm 1}
$$

lembrando que a temperatura diminui de modo inversamente proporcional ao parâmetro de escala: $T \propto a^{-1}$.

Para temperaturas menores, os $\chi$ 's são criados com baixas velocidades, e assim $E \approx$ $m c^{2}+\frac{p^{2}}{2 M_{\chi}}$, o que nos leva a

$$
n_{e q}=g \frac{4 \pi}{(2 \pi \hbar)^{3}}\left(2 M_{\chi} k T\right)^{\frac{3}{2}} e^{-\frac{M_{\chi} c^{2}}{k T}} \int_{0}^{\infty} x^{2} e^{-x^{2}} d x
$$

Enquanto há equilíbrio, a abundância de $\chi$ 's é governada por uma das duas equações acima. Percebemos que no caso não-relativístico a abundância de equilíbrio decresce exponencialmente com a diminuição da temperatura. Portanto, se os WIMPs tivessem se mantido em equilíbrio térmico com o plasma, sua abundância nos dias atuais seria desprezível.

Mas como os l's estão acoplados aos fótons, sua energia é compartilhada com eles e, à medida em que diminui a temperatura do universo, a energia dos l's também diminui. Até o ponto em que sua energia não é suficiente para criar $\chi$ 's, que continuam se aniquilando sem que haja uma "reposição" de sua abundância. Se esse processo continuasse, a abundância de $\chi$ 's rapidamente ficaria desprezível, mas a diminuição de sua densidade numérica diminui também a taxa de aniquilação $\left(n\left\langle\sigma_{A} v\right\rangle\right.$, com $\sigma_{A}$ sendo a seção de choque de aniquilação e $v$ sua velocidade) que, quase automaticamente, se torna comparável à taxa de expansão do universo. Neste instante, os $\chi$ 's saem do equilíbrio e tem fim o processo de desacoplamento que se iniciou com a impossibilidade de criação de $\chi$ 's a partir dos l's. A partir deste instante, a variação na abundância dos $\chi$ 's passa a ser governada apenas pela taxa de expansão do universo, ou seja, $n \propto a^{-3}$. A Figura 2.1 ilustra a evolução da abundância de $\chi$ 's no caso em que estas partículas tivessem continuado indefinidamente em equilíbrio e no caso da ocorrência do desacoplamento, para diferentes seções de choque de aniquilação.

O cálculo exato da abundância nos dias atuais envolve a resolução da equação de Boltzmann durante o processo de desacoplamento, o que requer um certo trabalho. É possível provar [21] que essa abundância, em termos da densidade crítica do universo $\rho_{c}$, é dada por $\frac{\rho_{\chi}}{\rho_{c}} \approx \frac{3 \times 10^{-27}}{\left\langle\sigma_{A} v\right\rangle}$, o que mostra que para a abundância de $\chi$ 's ser da ordem da abundância observada de ME, ou seja, $\frac{\rho_{\chi}}{\rho_{c}} \approx 0.3$, os $\chi$ 's de fato devem interagir com seções de choque da ordem das interações fracas $\left(\sigma_{A} \approx 10^{-34} \mathrm{~cm}^{2}\right)$.

O mais interessante é que há vários modelos de extensão do Modelo Padrão de 


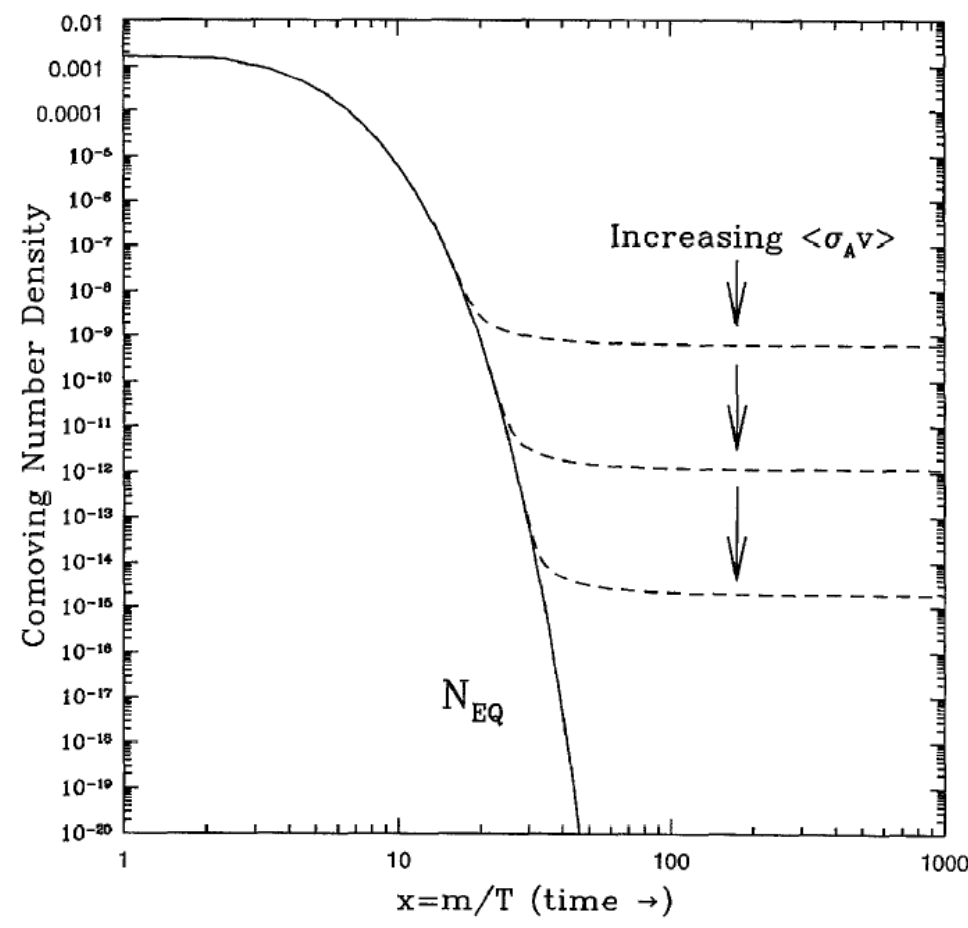

Figura 2.1: Evolução da abundância de ME. O eixo das ordenadas mostra a densidade numérica co-movente, ou seja, $n a^{3}$. O eixo das abscissas mostra a razão $M_{\chi} c^{2} / k T$ nas unidades naturais ( $\hbar=c=k=1$ ). São considerados o caso dos $\chi$ 's continuarem em equilíbrio indefinidamente e o caso da ocorrência do freeze-out para algumas seções de choque de aniquilação - extraído de [21].

partículas que prevêem justamente a existência de partículas massivas e fracamente interagentes, abrindo a possibilidade de que a constituição da ME seja naturalmente explicada com estes modelos. Entre estes modelos de extensão estão a supersimetria, que apresenta candidatos à ME como o neutralino ou o gravitino (a depender do cenário escolhido) e o modelo de dimensões extras universais, que têm as partículas Kaluza-Klein mais leves como candidatas.

\subsection{Partículas supermassivas}

O cálculo da abundância de WIMPs tem como hipótese básica seu equilíbrio térmico com o plasma no início do universo. Partículas que tenham experimentado este equilíbrio devem ter massas até cerca de $300 \mathrm{TeV}$ [23]. Entretanto, é possível que a ME seja constituída de partículas que nunca tenham compartilhado do equilíbrio térmico com o plasma. Para isso, é suficiente que a taxa de aniquilação $\Gamma=n\left\langle\sigma_{A} v\right\rangle$ tenha sido sempre menor que a taxa de expansão $H$, o que é garantido se sua massa for muito 
grande, lembrando que a densidade numérica pode ser escrita como $n=\frac{\rho_{\chi}}{M_{\chi}}$. Neste caso o equilíbrio térmico nunca é atingido, e depois de encerrado o processo de criação, a densidade numérica dessas partículas deve se comportar então como $n \propto a^{-3}$, garantindo uma abundância da ordem da medida hoje em dia.

Em termos numéricos, Chung, Kolb e Riotto [24] mostraram que o critério de nãoequilíbrio pode ser escrito como

$$
\left(\frac{200 T e V}{M_{\chi}}\right)^{2}\left(\frac{T_{*}}{M_{\chi}}\right)<1,
$$

onde $T_{*}$ é a temperatura do universo na época em que essas partículas foram criadas. Assim, é necessário estudar em que condições estas partículas podem ter sido criadas no início do universo, de modo a não entrarem em equilíbrio térmico e darem conta da abundância de ME observada. Alguns possíveis mecanismos de criação destas partículas ocorrem no fim da inflação [24].

Em um destes possíveis mecanismos, assume-se que toda a energia do ínflaton (campo escalar associado à inflação) é instantaneamente transmitida aos fótons, aquecendo o universo a uma temperatura $T_{R H}$ (definida como a temperatura a partir da qual tem início a Era da Radiação, normalmente assumida como $T_{R H} \approx 10^{9} \mathrm{GeV}$ ). Este processo é chamado de Reheating e está presente em vários modelos de inflação. Neste caso, dada a energia disponível no ínflaton a uma temperatura da ordem de $T_{R H}$, a massa dos $\chi$ 's é de cerca de $2,5 \times 10^{10} \mathrm{GeV}$, e $T_{R H}$ é a temperatura máxima do universo após a inflação.

Num segundo cenário, o Reheating não é instantâneo, e ocorre durante o decaimento do ínflaton. Como a temperatura do universo cai enquanto ele se expande, a temperatura máxima neste caso deve ter sido muito maior que $T_{R H}$, o que disponibiliza mais energia e possibilita a criação de partículas ainda mais massivas, com massas da ordem de $10^{12} \mathrm{GeV}$.

Outra possibilidade é que estas partículas tenham sido criadas numa etapa anterior ao Reheating, chamada de Pre-reheating, presente em alguns modelos inflacionários. Este processo envolve uma criação explosiva de partículas, com massas de até $10^{15} \mathrm{GeV}$.

Por fim estas partículas podem ter sido criadas na transição da fase inflacionária para a Era da Radiação, como consequência das flutuações quânticas do vácuo sobre o campo associado à ME, num processo parecido com aquele que gerou as primeiras inomogeneidades que dariam origem à formação de estruturas. Este processo poderia gerar partículas com massas da ordem de $10^{13} \mathrm{GeV}$. 


\subsection{Partículas supermassivas e fortemente interagentes}

Como vimos acima, partículas supermassivas garantem o não-equilíbrio com o plasma primordial, independentemente do tipo de interação que realiza com a matéria conhecida. Assim, fica aberta a possibilidade de seus constituintes interagirem fortemente com a matéria comum. Estas partículas são chamadas então de Strongly Interacting Massive Particle (SIMPs). Grande parte do espaço de fases massa versus seção-de-choque para os SIMPs já foi excluído em análises anteriores, como mostra a Figura 1.1 (análise do calor da Terra e Mina/Espaço).

Para massas ainda maiores, estas partículas são chamadas de Simpzillas (o zilla, bem, é uma brincadeira que remete ao Godzilla, por se tratar de massas gigantescas), a análise com detecção direta de ME - região amarela na Figura 1.1 - também permitiu excluir grande parte do espaço de fases, deixando apenas algumas lacunas. É o teste dessas lacunas que nos interessa neste projeto. Para simplificar, no restante do texto chamaremos de Simpzillas tanto os SIMPs quanto os próprios Simpzillas. 


\section{Capítulo 3}

\section{Experiências de detecção de ME}

Como mostram as observações citadas no primeiro capítulo, a nossa galáxia, como as outras, está envolta por um halo de ME. Por isso concluímos que o Sistema Solar está sendo atravessado pelas partículas $\chi$ que compõem a ME e que, portanto, podem ser detectadas em experiências montadas na Terra.

Podemos dividir esses experimentos em duas categorias gerais: detecção direta e detecção indireta. Na primeira, a passagem de $\chi$ 's registra um sinal nos detectores, enquanto na segunda se mede a passagem das partículas resultantes de aniquilações ou decaimentos $\operatorname{dos} \chi^{\prime}$ s.

Começaremos este capítulo com uma descrição sucinta das experiências de detecção direta e apresentando os resultados mais recentes. Depois descreveremos o funcionamento da experiência de detecção indireta que nos interessa aqui: a detecção de neutrinos resultantes da aniquilação dos $\chi$ 's no núcleo do Sol, tomando como exemplo o telescópio IceCube [2].

\subsection{Detecção direta}

Nas experiências de detecção direta de ME, o objetivo é registrar o sinal direto da passagem de um $\chi$ pelo detector, através da medida da energia de recuo $E_{R}$ transferida aos seus núcleos. Essa energia pode ser escrita como

$$
E_{R}=E \cdot 2 \frac{m_{r}}{\left(M_{\chi}+m_{N}\right)} \cdot\left(1-\cos \theta^{*}\right)
$$

onde $E$ é a energia inicial do $\chi$ incidente, $M_{\chi}$ e $m_{N}$ são as massas do $\chi$ e do núcleo-alvo respectivamente, $m_{r}=\frac{M_{\chi} m_{N}}{M_{\chi}+m_{N}}$ a massa reduzida e $\theta^{*}$ é o ângulo de espalhamento no referencial do centro de massa.

Todas as experiências deste tipo têm em comum a necessidade de: instalar os de- 
tectores em arranjos subterrâneos para diminuir o fundo de raios cósmicos; envolver os detectores em "escudos" de materiais que impeçam ou diminuam a passagem de nêutrons e utilizar materiais de baixa emissão de radiação para minimizar sua interferência no sinal desejado.

Antes de chegar aos detectores, os $\chi$ 's devem viajar uma certa distância no interior da Terra. Para partículas que interagem fortemente, a perda de energia durante esse trajeto é considerável. Nestes casos, depois de incidir na Terra com energia inicial $E_{0}$ e atravessar uma distância $l$, os $\chi$ 's devem chegar ao detector com energia $E=E_{0} e^{-\frac{2 \rho N_{A} \sigma_{\chi N}}{M_{\chi}} l}$, onde $\rho$ é a densidade em cada ponto da Terra, $N_{A}$ o número de Avogadro e $\sigma_{\chi N}$ é a seção de choque de interação $\chi$-núcleo. No caso de partículas fracamente interagentes esta perda de energia é desprezível, já que a seção de choque com os núcleos no interior da Terra é pequena.

Depois de calculada a perda de energia no interior da Terra e eliminadas todas as fontes de ruído e de fundo indesejado, é contabilizada a taxa de eventos atribuída à passagem dos $\chi$ 's. Um modo de testar a composição da ME é comparar esta taxa com a taxa prevista por um determinado modelo. Assim se verifica a possibilidade de existência da partícula em questão, construindo-se uma região de exclusão no espaço de fases massa versus seção de choque.

O cálculo da taxa prevista depende de alguns parâmetros e as principais hipóteses a serem assumidas referem-se às características da seção de choque (por exemplo se é dependente ou independente de spin e a escolha do fator de forma $F\left(E_{R}\right)$ ) e à distribuição de velocidades $f\left(\vec{v}, \overrightarrow{v_{\oplus}}\right)$, sendo $\overrightarrow{v_{\oplus}}$ a velocidade da Terra em relação ao halo galático. Pode-se mostrar que a taxa diferencial prevista (independente de spin) é dada por

$$
\frac{d R}{d E_{R}}=m_{N} \frac{N_{A}}{A} \frac{\sigma_{\chi N}}{2 m_{r}^{2}} F^{2}\left(E_{R}\right) \frac{n_{0}}{k} \int_{v_{\min }}^{v_{e s c}} \frac{f\left(\vec{v}, \overrightarrow{v_{\oplus}}\right)}{v} d^{3} \vec{v}
$$

onde $n_{0}=\frac{\rho_{\chi}}{M_{\chi}}$ é a densidade numérica média de ME nos arredores do $\mathrm{Sol}^{1}, k$ é uma constante de normalização, $v_{\text {min }}$ é a velocidade mínima que o $\chi$ deve ter para transmitir uma energia de recuo $E_{R}$ ao núcleo alvo e $v_{e s c} \approx 600 \mathrm{~km} / \mathrm{s}$ é a velocidade de escape local da Galáxia.

Na sequência, vamos exemplificar este tipo de detecção, descrevendo algumas experiências atuais.

\footnotetext{
${ }^{1} \mathrm{~A}$ densidade $\rho_{\chi} \approx 0,01 M_{\odot} / p c^{3} \approx 0.3 \mathrm{GeV} / \mathrm{cm}^{3}$ nos arredores do Sol pode ser obtida a partir da curva de rotação da Via Láctea [25].
} 


\subsubsection{CDMS}

O Cryogenic Dark Matter Search (CDMS) [26] é uma experimento projetado para medir a energia de recuo dos núcleos nos detectores a temperaturas criogências $(<50 \mathrm{mK})$. Está localizado atualmente na Mina Soudan, em Minnesota - EUA, a cerca de $700 m$ de profundidade.

Seus detectores são capazes de distinguir com bastante precisão sinais provenientes de recuos nucleares (produzidos por $\chi$ 's ou nêutrons) de sinais de recuos eletrônicos (produzidos por fótons ou elétrons incidentes), através da medida simultânea dos fônons e da ionização gerados pela passagem dessas partículas. Essa distinção é possível porque recuos eletrônicos produzem maior ionização que os nucleares. A Figura 3.1 ilustra essa distinção, que permite excluir o fundo gerado por elétrons e fótons. A exclusão do fundo de nêutrons é feita principalmente através dos escudos em volta dos detectores.

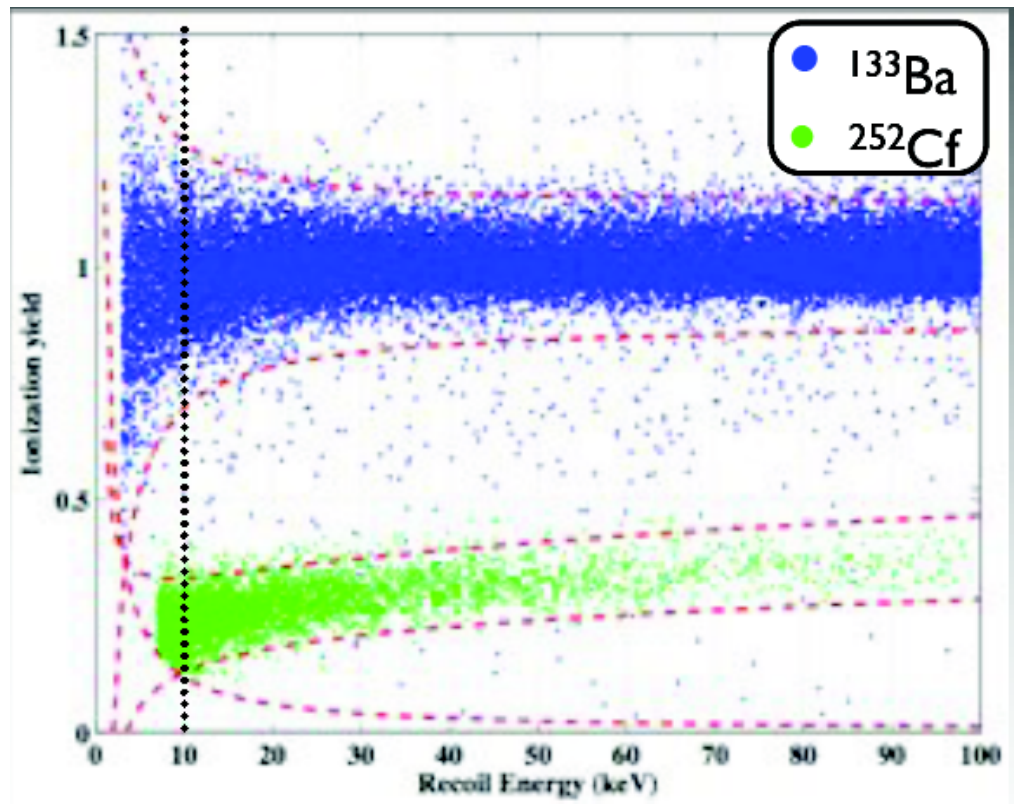

Figura 3.1: Distinção dos sinais devidos a recuos nucleares ou eletrônicos. Estes últimos produzem maior ionização que os primeiros. O eixo y mostra a ionização produzida (razão entre as energias de ionização e de recuo). Os pontos azuis representam recuos eletrônicos no interior do detector e os pontos verdes representam recuos nucleares - extraído de [27].

Em seu artigo mais recente [26], o CDMS II reporta ter observado dois eventos em acordo com as expectativas para eventos produzidos por WIMPs, embora haja uma probabilidade de $23 \%$ desses eventos serem atribuídos ao fundo ("background"). Seus autores consideram que "os resultados dessa análise não podem ser interpretados como evidência significativa de interações do WIMP, e nem podemos rejeitar os eventos como espalhamento de WIMPs". A zona de exclusão obtida por eles, junto com a obtida por outros 
grupos, é mostrada na Figura 3.2. Também são mostradas as regiões permitidas nas previsões teóricas de alguns modelos supersimétricos (regiões verde e cinza). As regiões acima das curvas estão excluídas.

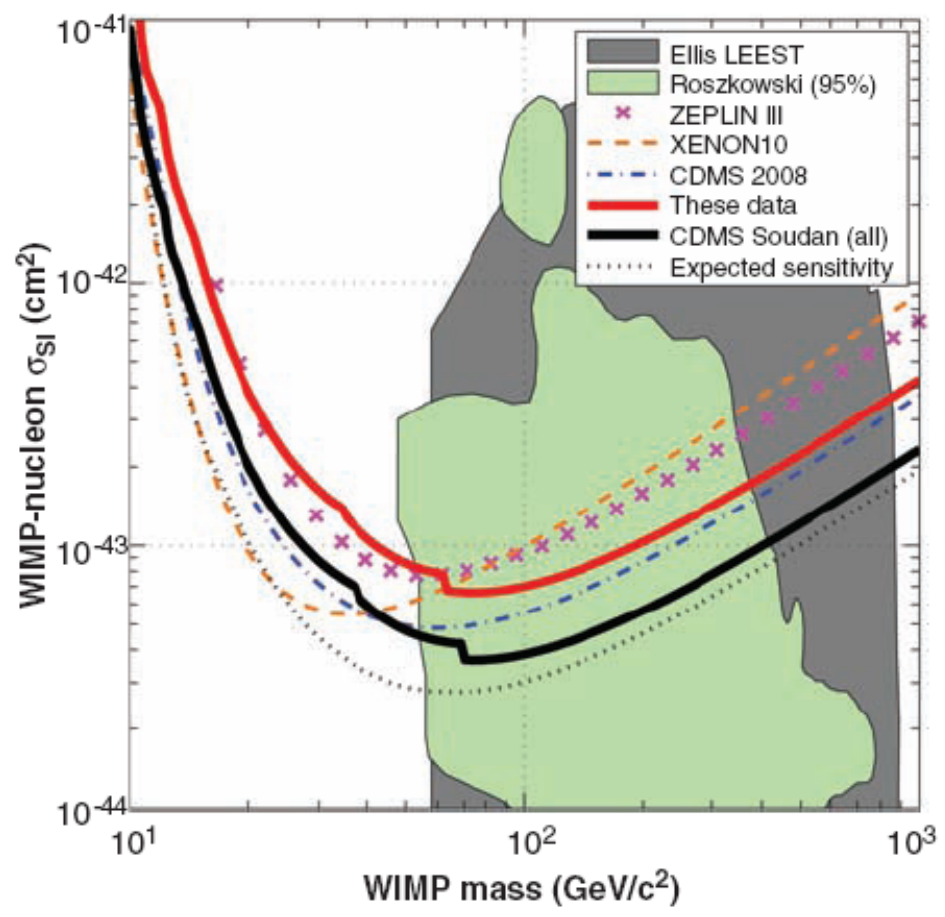

Figura 3.2: Atual zona de exclusão publicada pelo CDMS II [26]. As curvas mostradas indicam um limite superior, com nível de confiança de $90 \%$, para a seção de choque (independente de spin), em função da massa. A curva vermelha contínua mostra o limite obtido com os últimos dados e a linha contínua preta mostra o limite obtido combinandose os dados atuais com resultados anteriores do CDMS II.

\subsubsection{DAMA}

O DArk MAtter (DAMA) [28] está localizado no Gran Sasso National LaboratoryItália sob uma montanha de $\approx 1400 \mathrm{~m}$. Seu principal objetivo é medir as modulações anuais no sinal de ME devido ao movimento de rotação da Terra em torno do Sol. Em determinada época do ano, a velocidade da Terra se soma à velocidade do Sistema Solar em torno da Galáxia, e seis meses depois ela é subtraída, como mostra a Figura 3.3. A projeção da velocidade da Terra no plano galático pode então ser escrita como $v_{\oplus}(t)=$ $v_{\odot}+v_{T S} \cos \gamma \cos \omega\left(t-t_{0}\right)$, onde $v_{\odot} \approx v_{0}+12 \mathrm{~km} / \mathrm{s}$ é a velocidade do Sol com relação ao centro galático, $v_{0}$ é a velocidade local obtida da curva de rotação da Via Láctea, $\gamma$ é o ângulo de inclinação da órbita da Terra em torno do Sol com relação ao plano galático e $v_{T S} \approx 30 \mathrm{~km} / \mathrm{s}$ é a velocidade da Terra em torno do Sol. 


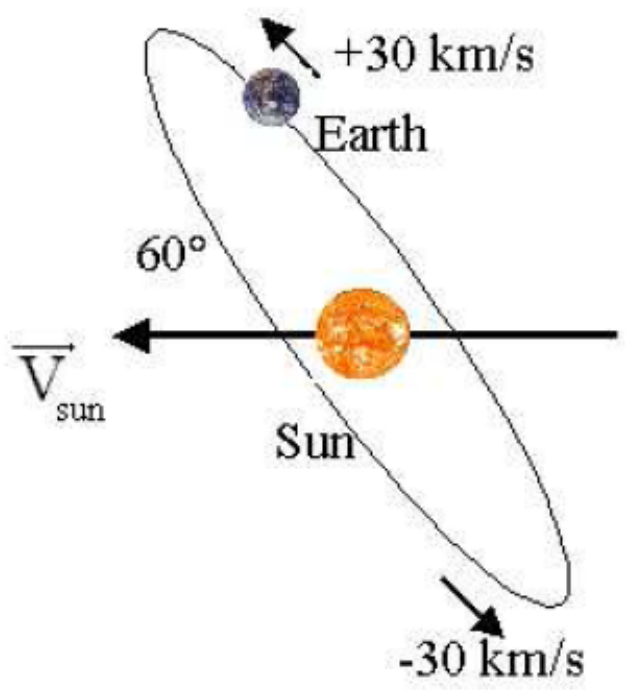

Figura 3.3: Ilustração do movimento de translação da Terra ao redor do Sol e do movimento do Sol em relação ao centro galático - extraído de [28].

Essa oscilação em $v_{\oplus}(t)$ se reflete na taxa diferencial esperada (equação 3.2), que pode ser medida com bastante precisão. Ao utilizar esta técnica, o DAMA opta por não identificar e eliminar os fundos sempre presentes nestes experimentos. Assim, é capaz de medir essa oscilação independentemente da composição do halo galático. Seu resultado é mostrado na Figura 3.4 .

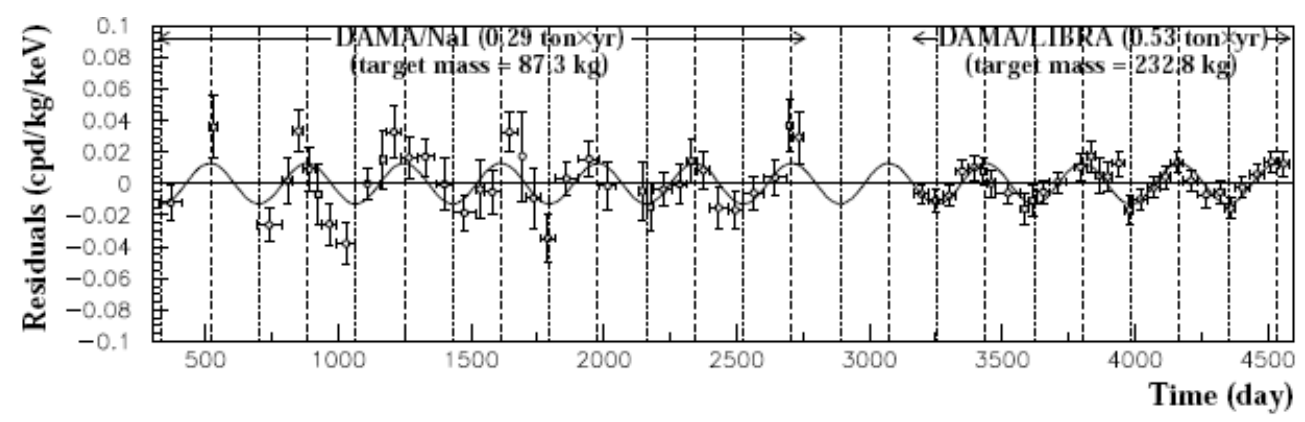

Figura 3.4: Medidas atuais da modulação anual do sinal obtidas pelo DAMA [29] em duas etapas, a primeira obtida com o DAMA/NaI e a segunda com o DAMA/LIBRA. As linhas verticais indicam as posições previstas teoricamente para os máximos e mínimos do sinal.

Se essa oscilação é de fato devida à passagem dos $\chi$ 's, esse resultado constitui uma detecção direta de ME. No entanto, a região de parâmetros permitida pelo DAMA é incompatível com as curvas de exclusão obtidas por muitas outras experiências de detecção direta de ME, como mostrado nas Figuras 3.5 e 3.6. Há várias tentativas de compatibili- 
zar estes sinais [31-34] com as regiões de exclusão das outras experiências, mas até agora isso não foi possível.

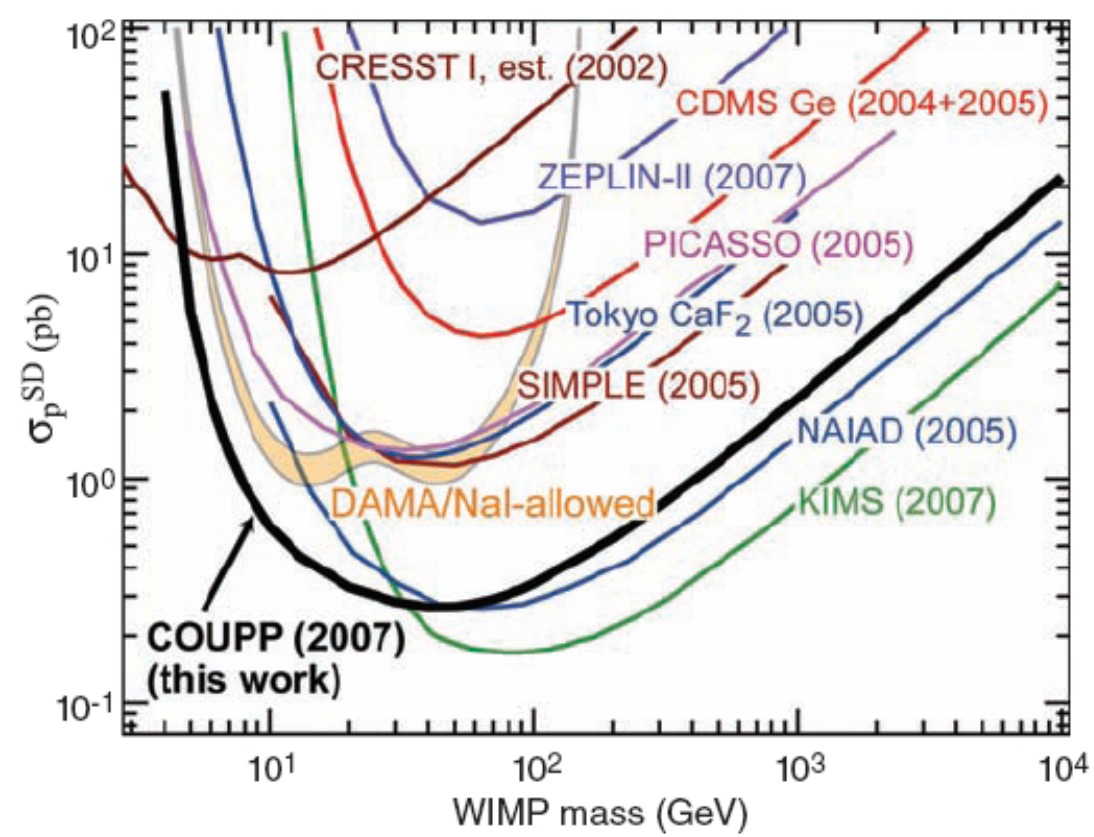

Figura 3.5: Curvas de exclusão de várias experiências realizadas até 2008. As regiões acima destas curvas estão excluídas. Também é mostrada (em amarelo) a região permitida pelo DAMA dentro da zona de exclusão das outras experiências. Extraído de [30].

\subsubsection{XENON100}

Esta experiência, continuação do XENON10 [35], também está localizada no Gran Sasso National Laboratory, e tem como objetivo detectar a passagem de WIMPs em Xenônio líquido. A técnica de detecção, como no CDMS, também permite distinguir sinais de recuos nucleares de sinais de recuos eletrônicos, mas aqui isso é feito através da medida da cintilação direta produzida numa parte líquida e da ionização seguida de cintilação proporcional em uma parte gasosa.

Os resultados atuais publicados por esta experiência são mostrados na Figura 3.6. Também são mostradas as curvas de exclusão do CDMS e as previsões do DAMA, em que se nota a incompatibilidade destas últimas com os primeiros.

\subsection{Detecção Indireta}

Nas experiências deste tipo, o objetivo é detectar produtos da aniquilação (ou decaimento) de $\chi$ 's. Essas aniquilações podem ocorrer em qualquer ponto do halo, mas 


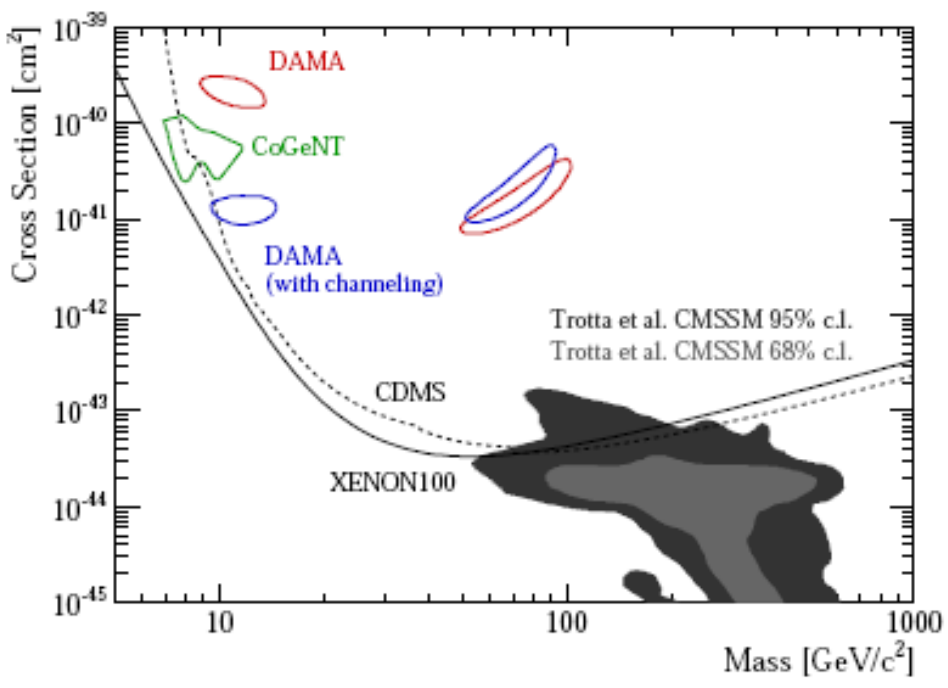

Figura 3.6: Limite superior da seção de choque (independente de spin), em função da massa do WIMP, obtida pelo XENON100 [36]. Também são mostradas a curva obtida pelo CDMS e o resultado do DAMA. Note-se a incompatibilidade desta última com as medidas do XENON100 e do CDMS. Extraído de [36].

a probabilidade de aniquilação aumenta com a densidade da região onde elas ocorrem. Por isso, regiões como o núcleo de estrelas e o centro galático são potencialmente mais interessantes, gerando fluxos mais intensos das partículas resultantes. Estas partículas podem ser muito diversas, a depender do modelo adotado. Em particular, podem ser produzidos neutrinos, raios- $\gamma$ e anti-partículas como pósitrons e anti-prótons. Por isso há algumas experiências que pretendem medir sinais dessas partículas que possam ser associados à ME para inferir suas propriedades. Por exemplo, há estudos que atribuem um excesso de pósitrons no halo galático, observado pelo PAMELA ${ }^{2}$ às aniquilações de ME.

Outra possibilidade é que as aniquilações de $\chi$ 's em outras galáxias gerem um excesso de raios- $\gamma$ que não pode ser atribuído a processos conhecidos. Em artigo recente [39], o Fermi-LAT reporta não ter observado tal excesso num conjunto de 14 anãs-brancas selecionadas, mas seus dados continuam sendo analisados.

As aniquilações de $\chi$ 's também podem dar origem a neutrinos. Isso pode ocorrer diretamente ou através do decaimento das partículas geradas nas aniquilações. Para detectá-los, é possível utilizar-se os chamados telescópios de neutrinos, que são experiências cujo objetivo é detectar neutrinos resultantes de eventos astrofísicos. Atualmente os principais telescópios de neutrinos em operação são o ANTARES e o IceCube. O primeiro está localizado no Mar Mediterrâneo a cerca de $2500 \mathrm{~m}$ de profundidade, e seu funcionamento

\footnotetext{
${ }^{2}$ Payload for Antimatter Matter Exploration and Light-nuclei Astrophysics - [37].
} 
é análogo ao do IceCube (que será explicado na sequência), sendo que o ANTARES usa o oceano como meio de propagação das partículas de interesse e tem um volume da ordem de $10^{-2} \mathrm{~km}^{3}$, enquanto o IceCube usa o gelo e tem um volume de $1 \mathrm{~km}^{3}$.

\subsubsection{O IceCube}

Este telescópio, situado no gelo do Pólo Sul, está sendo construído com o objetivo de detectar neutrinos de altas energias (da ordem de $10^{2} \mathrm{GeV}$ até $10^{12} \mathrm{GeV}$ ) vindos de eventos astrofísicos. Ele pode detectar neutrinos gerados em supernovas e gamma ray bursts, e também é capaz de detectar os neutrinos resultantes das aniquilações dos $\chi$ 's. O experimento é constituído de cabos posicionadas verticalmente no gelo, em cada um dos quais são fixadas 60 fotomultiplicadoras (PMTs) - Figura 3.7. As posições dos cabos são tais que as PMTs nas extremidades ficam às profundidades de $1400 \mathrm{~m}$ e $2400 \mathrm{~m}$ e a distância horizontal entre eles é de $125 \mathrm{~m}$.

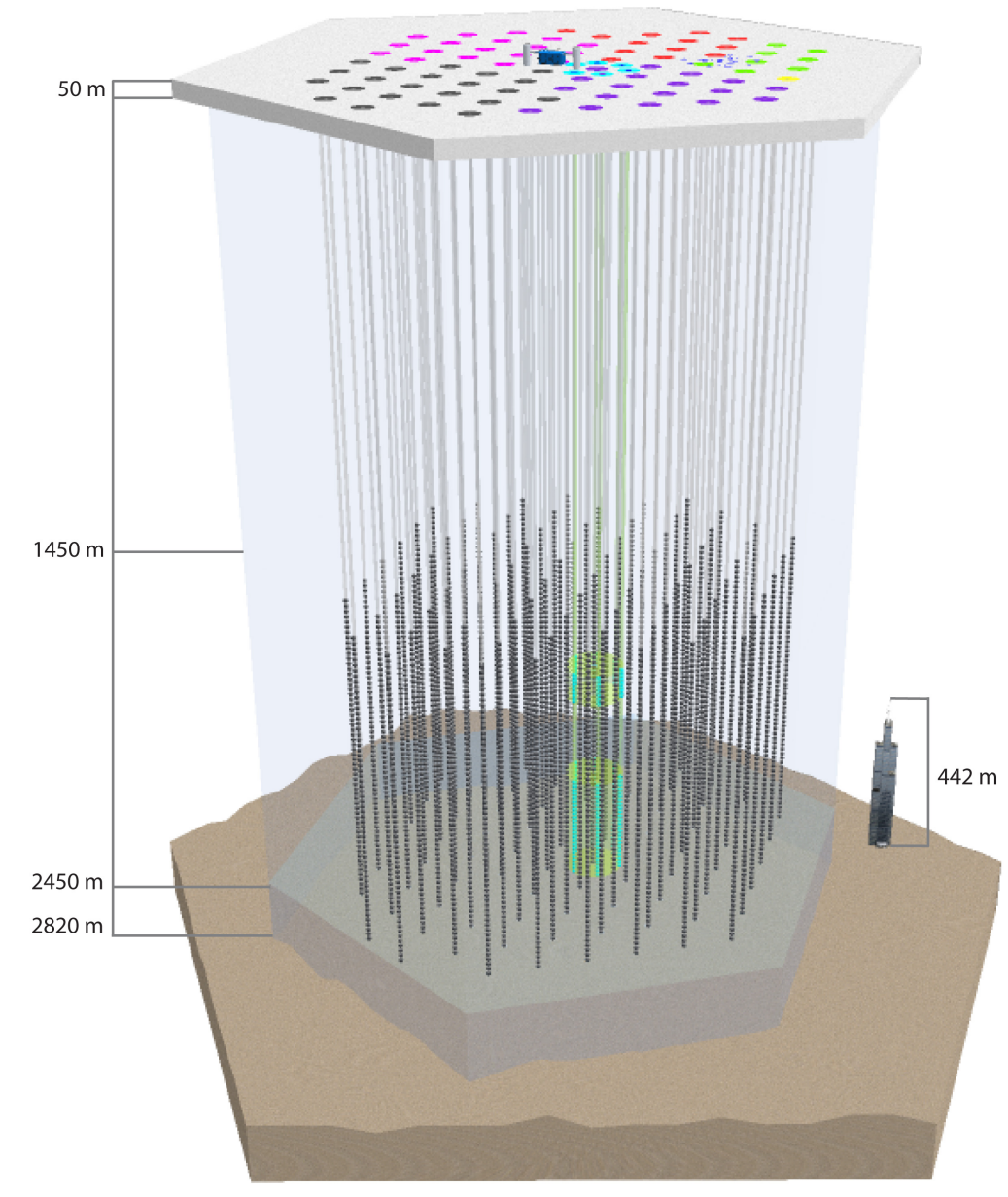

Figura 3.7: Ilustração do IceCube em escala [42]. A parte central em verde representa o Deep Core. 
O esquema de detecção é simples: os neutrinos incidentes precisam interagir com os núcleos da Terra e gerar muons através de interações de corrente carregada. Esses muons, ao viajar no gelo, emitem radiação Cherenkov que é finalmente detectada nas PMTs. A análise dos sinais de diferentes PMTs permite deduzir a trajetória do muon - Figura 3.8. Como o muon gerado mantém a direção de movimento do neutrino incidente, a trajetória deste fica assim determinada.

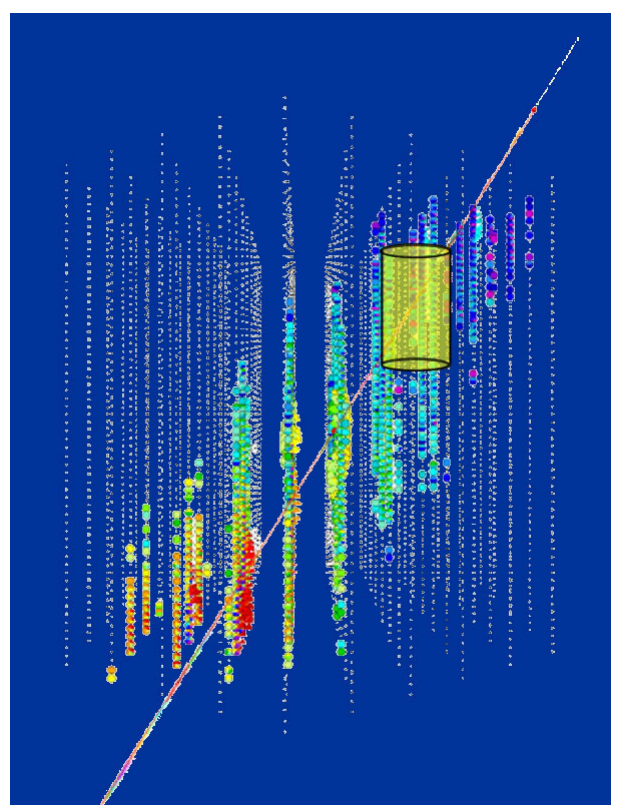

Figura 3.8: Esquema de detecção de um muon [42]. Os pontos em vermelho indicam as primeiras PMTs ativadas e os verdes as últimas.

Um ponto que dificulta o processo de medição é que há um grande fluxo de muons gerados por interações de raios cósmicos na atmosfera, os chamados muons atmosféricos. Para diminuir esse fundo, é necessário selecionar eventos que chegam "de baixo para cima", ou seja, abaixo do horizonte do telescópio, usando a Terra como escudo para os muons atmosféricos.

Até agora, já foram instalados 79 cabos dos 86 previstos para a experiência [40], sendo que 6 deles constituem o chamado Deep Core, um arranjo central com PMTs de maior eficiência e mais próximas umas das outras. A análise dos dados tomados no estágio em que tinha apenas 22 cabos instalados, já possibilitou a publicação de resultados importantes [43,44], inclusive os de interesse em nosso projeto [44]. 


\section{Capítulo 4}

\section{Espectro de neutrinos resultantes das aniquilações de $\chi$ 's no Sol}

A partir deste capítulo, descreveremos a investigação que permite testar o espaço de fase massa versus seção de choque ainda permitido a candidatos massivos e fortemente interagentes. Investigamos a detecção de neutrinos produzidos pelas aniquilações de Simpzillas no núcleo do Sol, com vistas à comparação do sinal previsto com os resultados publicados pelo IceCube $[43,44]$. Neste capítulo determinamos o espectro de neutrinos resultantes destas aniquilações.

\subsection{Aniquilações no núcleo do Sol}

Podemos escrever o fluxo de neutrinos de um tipo $i$ esperado na Terra, resultantes das aniquilações de Simpzillas, como [21]

$$
\left(\frac{d \phi}{d E}\right)_{i}=\frac{\Gamma_{A}}{4 \pi R^{2}} \sum_{F} B_{F}\left(\frac{d N}{d E}\right)_{F, i}
$$

onde $\Gamma_{A}$ é a taxa de aniquilação e $R$ é a distância Terra-Sol. A somatória é sobre todos os canais de aniquilação, $B_{F}$ é a razão de ramificação, ou seja, o fator de ponderação com que cada processo contribui ao fluxo total de neutrinos e $\left(\frac{d N}{d E}\right)_{F, i}$ é o espectro de energia dos neutrinos que emergem do Sol.

Dentre todas as partículas geradas por estas aniquilações, as únicas que conseguem escapar do Sol são os neutrinos, devido à sua baixa seção de choque de interação com os núcleos. O espectro resultante pode ser distinguido daquele associado aos chamados neutrinos solares (produtos das reações nucleares) porque a energia típica destes últimos é da ordem de alguns $M e V$, enquanto a energia típica daqueles deve ser da ordem de 
centenas de $\mathrm{GeV}$ ou mais, dadas as massas previstas dos $\chi$ 's. Esse espectro se altera bastante, desde sua origem no núcleo do Sol até a superfície. Isso ocorre devido às interações com os nucleons e às oscilações entre os diferentes sabores, conforme explicaremos na seção dedicada à propagação destes neutrinos.

\section{A taxa de aniquilação}

A quantidade $N$ de $\chi$ 's no núcleo do Sol aumenta com a captura destas partículas e diminui com suas aniquilações. A taxa de aniquilação (por partícula) é dada por $n\left\langle\sigma_{A} v\right\rangle$, onde $n$ é a densidade numérica de $\chi$ 's no núcleo do Sol, $\sigma_{A}$ é a seção de choque de aniquilação e $v$ velocidade relativa entre dois $\chi$ 's. Assim, a evolução temporal da quantidade de $\chi$ 's no Sol é governada pela equação

$$
\frac{d N}{d t}=\Gamma_{C}-2 \Gamma_{A}=\Gamma_{C}-C_{A} N^{2}
$$

onde $\Gamma_{C}$ é a taxa de captura, $\Gamma_{A}=N \cdot n\left\langle\sigma_{A} v\right\rangle$ é a taxa total de aniquilação, com $C_{A}=2 \frac{\left\langle\sigma_{A} v\right\rangle}{V}$, sendo $V$ o volume efetivo onde ocorrem as aniquilações e o fator 2 é devido a que cada aniquilação elimina $2 \chi$ 's. Assumindo que a densidade média de $\chi$ 's no halo galático não muda, a taxa de captura não depende do tempo e a integração da equação acima resulta em

$$
N(t)=\sqrt{\frac{\Gamma_{C}}{C_{A}}} \operatorname{tgh}\left(\sqrt{\Gamma_{C} C_{A}} t\right)
$$

e portanto a taxa total de captura é dada por

$$
\Gamma_{A}=\frac{1}{2} C_{A} N^{2}=\frac{1}{2} \Gamma_{C} \operatorname{tgh}^{2}\left(\frac{t}{\tau}\right)
$$

onde $\tau=\frac{1}{\sqrt{\Gamma_{C} C_{A}}}$ é um tempo característico de equilíbrio. Para um tempo suficientemente grande a taxa de aniquilação será

$$
\Gamma_{A}=\frac{1}{2} \Gamma_{C}
$$

É possível mostrar que $\tau$ é muito menor que a idade do Sistema Solar, portanto o equilíbrio já foi atingido e a taxa de aniquilação é de fato dada pela expressão acima. Passaremos agora ao cálculo da taxa de captura, detalhando depois os desenvolvimentos feitos para prever o espectro de neutrinos saindo do Sol. 


\subsection{A taxa de captura}

O número de partículas, com distribuição de velocidades $f(u)$, que atravessam uma dada superfície por unidade de tempo é dado por

$$
F=\int f(u) d u \vec{u} \cdot \hat{n} d S
$$

onde $\hat{n}$ é o versor orientado da superfície de elemento de área $d S$.

Vamos usar esta expressão para determinar o número de partículas por unidade de tempo atravessando uma superfície esférica imaginária com origem no centro do Sol e com raio $R$ muito grande, onde o campo gravitacional do Sol seja desprezível. Usando coordenadas esféricas temos

$$
F=\pi R^{2} \int f(u) u d u d\left(\operatorname{sen}^{2} \theta\right)
$$

Por se tratar de um potencial central, podemos explorar a conservação do momento angular. Este (por unidade de massa) é dado por $J=r v \operatorname{sen} \theta$, onde $v$ é a velocidade da partícula em cada ponto, que pode ser escrita em termos de sua velocidade "no infinito" $u$ e da velocidade de escape em cada ponto $v_{e s c}(r)$ :

$$
v^{2}(r)=u^{2}+v_{e s c}^{2}(r)
$$

Com isto,

$$
F=\pi R^{2} \int_{0}^{\infty} f(u) u d u \int_{0}^{R^{2} v^{2}} \frac{d J^{2}}{R^{2} u^{2}} .
$$

Tomando $R=R_{\odot}$ (raio do Sol), o número de partículas atravessando essa superfície esférica por unidade de tempo fica

$$
F=\pi \int_{0}^{\infty} f(u) u d u \int_{0}^{R_{\odot}^{2} v_{\odot}^{2}} \frac{d J^{2}}{u^{2}} .
$$

em que $v_{\odot}^{2}=u^{2}+v_{\text {esc }}^{2}\left(R_{\odot}\right)$ e a velocidade de escape na superfície do Sol é $v_{\text {esc }}\left(R_{\odot}\right)=$ $618 \mathrm{~km} / \mathrm{s}$.

A taxa de captura será dada por

$$
\Gamma_{C}=\pi \int_{0}^{\infty} f(u) u d u \int_{0}^{R_{\odot}^{2} v_{\odot}^{2}} \frac{d J^{2}}{u^{2}} P(J, u),
$$

onde $P(J, u)$ é a probabilidade de uma partícula ser capturada, dado que ela tenha atravessado a superfície em questão. 
Essa probabilidade $P(J, u)$ pode ser escrita como o produto da probabilidade $P_{1}$ de haver uma colisão entre um $\chi$ e um nucleon, com a probabilidade $P_{2}$ dessa interação resultar numa velocidade menor que a velocidade de escape. Dado que estas probabilidades são diferentes para partículas que interagem fraca ou fortemente, vamos determiná-las nos dois casos.

\section{WIMPs}

No caso de WIMPs [41,47], que interagem através da força fraca, a probabilidade de haver uma interação é muito pequena $\left(n \sigma R_{\odot} \ll 1\right)$. Pode-se, então, estabelecer como critério de captura que a velocidade do $\chi$ depois de uma interação fique menor que a velocidade de escape naquele ponto.

A probabilidade $P_{1}$ de haver uma interação deve depender da distância $l$ percorrida dentro do Sol e do momento angular $J$ da partícula incidente (onde se implicitam todas as dependências angulares). A distância $d l$ percorrida em uma camada de espessura infinitesimal $d r$ pode ser escrita como $d l=\frac{d r}{\cos \theta}=\frac{d r}{\sqrt{1-\left(\frac{J}{r v}\right)^{2}}}$, onde $\theta$ é o ângulo entre a velocidade de incidência e a normal à superfície. A probabilidade é calculada integrandose a probabilidade de interação na camada, $n \sigma d l$, e integrando-se sobre os possíveis valores de $J$ em cada ponto, normalizando por todos os seus possíveis valores em todos os pontos (do centro à superfície do Sol), lembrando que a partícula pode passar duas vezes pela mesma camada:

$$
P_{1}=\frac{\int_{0}^{R_{\odot}} d r \int_{0}^{r^{2} v^{2}} d J^{2} \frac{2 n \sigma}{\sqrt{1-\left(\frac{J}{r v}\right)^{2}}}}{\int_{0}^{R_{\odot}^{2} v_{\odot}^{2}} d J^{2}} .
$$

Para o cálculo da probabilidade $P_{2}$, da interação resultar numa velocidade menor que a velocidade de escape, vamos utilizar a expressão 3.1, obtida da cinemática de colisão entre dois corpos. A energia transferida à partícula alvo de massa $m_{N}$ (neste caso um nucleon no interior do Sol), inicialmente parada, pela partícula incidente de massa $M_{\chi}$ com energia $E$, é dada por $E_{R}$. Portanto a variação relativa da energia do $\chi$ incidente é $\frac{\Delta E}{E}=2 \frac{m_{r}}{\left(M_{\chi}+m_{N}\right)} \cdot\left(1-\cos \theta^{*}\right)$, onde fizemos $\Delta E=E_{R}$. Avaliando os limites de $\cos \theta^{*}$, conclui-se que esta variação relativa da energia deve estar no intervalo

$$
0 \leq \frac{\Delta E}{E} \leq 4 \frac{\mu}{(\mu+1)^{2}}
$$

com $\mu=\frac{M_{\chi}}{m_{N}}$. Para que a interação resulte numa velocidade menor que a de escape no ponto devemos ter $\frac{\Delta E}{E} \geq \frac{v^{2}-v_{e s c}^{2}}{v^{2}}=\frac{u^{2}}{v^{2}}$. Portanto, dado todo o intervalo 4.3, a partícula 
só será capturada quando

$$
\frac{u^{2}}{v^{2}} \leq \frac{\Delta E}{E} \leq 4 \frac{\mu}{(\mu+1)^{2}}
$$

Como esse espalhamento é isotrópico, a função de distribuição de $\frac{\Delta E}{E}$ deve ser constante no intervalo 4.3, o que nos permite calcular a probabilidade de $\frac{\Delta E}{E}$ estar no intervalo 4.4 como a fração que ele representa do intervalo total 4.3:

$$
P_{2}=\frac{4 \frac{\mu}{(\mu+1)^{2}}-\frac{u^{2}}{v^{2}}}{4 \frac{\mu}{(\mu+1)^{2}}}
$$

Portanto, a expressão da probabilidade de captura $P(J, u)$ para WIMPs é dada por:

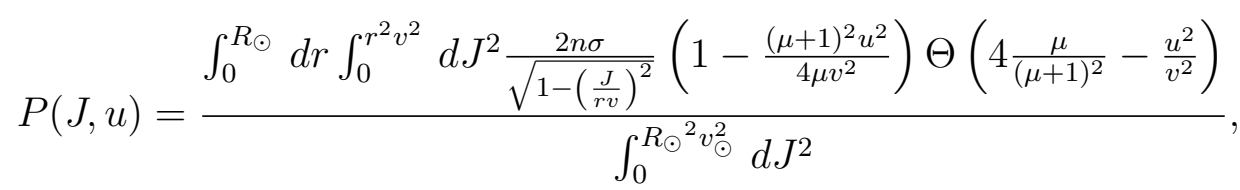

onde a função $\Theta(x)$ vale 1 para $x>1$ e 0 para $x<0$.

\section{Simpzillas}

No caso dos Simpzillas [47], a probabilidade de interação no interior do Sol é grande, já que eles interagem através da força forte com os nucleons, podendo um mesmo Simpzilla colidir muitas vezes até ser capturado. Por isso podemos igualar a probabilidade $P_{1}$ de haver uma interação a 1 e para ser capturada a partícula deve ser espalhada, depois de

$$
N=n \sigma R_{\odot}
$$

colisões, para uma velocidade menor que a velocidade de escape na superfície do Sol.

Como as massas previstas para o Simpzilla são muito maiores que as massas dos nucleons no Sol, podemos fazer $\frac{\mu}{(\mu+1)^{2}} \approx \frac{1}{\mu}$ e então $0 \leq \frac{\Delta E}{E} \leq \frac{4}{\mu}$. Assim, podemos dizer que, numa interação, $\frac{\Delta E}{E} \approx \frac{1}{\mu}$, e depois de $N$ interações a energia da partícula será $E\left(1-\frac{1}{\mu}\right)^{N}$ e portanto sua velocidade será $v_{\odot}^{2}\left(1-\frac{1}{\mu}\right)^{N}$. Escrevendo esta última em termos da velocidade "no infinito" $u$ e da velocidade de escape no ponto $v_{\text {esc }}(r)$, temos $\left(u^{2}+v_{\text {esc }}^{2}\left(R_{\odot}\right)\right)\left(1-\frac{1}{\mu}\right)^{N}$. Então, para haver captura devemos ter $\left(u^{2}+v_{e s c}^{2}\left(R_{\odot}\right)\right)\left(1-\frac{1}{\mu}\right)^{N} \leq v_{e s c}^{2}\left(R_{\odot}\right)$, ou seja,

$$
u \leq u_{\star},
$$

com $u_{\star}=\frac{v_{e s c}\left(R_{\odot}\right)}{\sqrt{\frac{\mu}{N}-1}}$, onde usamos o fato de que $\frac{1}{\mu} \ll 1$. Note-se que se $N \geq \mu \Rightarrow u_{\star} \rightarrow \infty$.

Tendo em vista a expressão geral 4.2, onde fazemos então $P(J, u)=1$ e alteramos o 
limite superior da integral em $d u$, a taxa de captura de Simpzillas é dada por

$$
\Gamma_{C}=\pi \int_{0}^{u_{\star}} \frac{f(u)}{u} R_{\odot}^{2} v_{\odot}^{2} d u=\pi R_{\odot}^{2} \int_{0}^{u_{\star}} \frac{f(u)}{u}\left[u^{2}+v_{e s c}^{2}\left(R_{\odot}\right)\right] d u .
$$

Utilizando a função de distribuição de velocidades de Maxwell-Boltzmann a uma temperatura $T$ com velocidade mais provável $u_{0}=\sqrt{\frac{2 k T}{M_{\chi}}}$,

$$
f(u)=4 \frac{n_{\chi}}{\sqrt{\pi u_{0}^{2}}}\left(\frac{u}{u_{0}}\right)^{2} e^{-\left(\frac{u}{u_{0}}\right)^{2}},
$$

onde $n_{\chi}$ é a densidade numérica local de Simpzillas, a taxa de captura dos Simpzillas fica finalmente

$$
\Gamma_{C}=2 \sqrt{\pi} n_{\chi} R_{\odot}^{2} u_{0}\left(1+y^{2}\right), \operatorname{para} N \geq \mu
$$

$\mathrm{e}$

$$
\Gamma_{C}=2 \sqrt{\pi} n_{\chi} R_{\odot}^{2} u_{0}\left[1+y^{2}-e^{-x^{2}}\left(1+y^{2}+x^{2}\right)\right], \operatorname{para} N<\mu
$$

onde foram introduzidos os parâmetros adimensionais $y=\frac{v_{e s c}\left(R_{\odot}\right)}{u_{0}}$ e $x=\frac{u_{\star}}{u_{0}}=\frac{y}{\sqrt{\frac{\mu}{N}-1}}$. A razão $\frac{\mu}{N}$ é calculada utilizando-se a densidade média do Sol $\rho_{\odot}: \frac{\mu}{N}=\frac{M_{\chi}}{\rho_{\odot} \sigma R_{\odot}}=\frac{4 \pi}{3} \frac{R_{\odot}^{2}}{M_{\odot}} \frac{M_{\chi}}{\sigma}$. Além disso, a utilização da distribuição de velocidades acima indica que desprezamos o movimento do Sol ao redor do centro galático.

Na Figura 4.1 mostramos nossos resultados para a taxa de captura em função da massa do Simpzilla para algumas seções de choque Simpzilla-nucleon. Nestes cálculos utilizamos $\rho_{\chi}=0.3 \mathrm{GeV} / \mathrm{cm}^{3}$ e $u_{0}=240 \mathrm{~km} / \mathrm{s}$. Estes resultados são compatíveis com os obtidos por [47].

De posse desta taxa, e consequentemente da taxa de aniquilação, somos capazes de determinar o espectro de neutrinos no núcleo do Sol. A partir deste espectro, podemos calcular o fluxo de neutrinos chegando à Terra e ao detector.

\subsection{O espectro de neutrinos no núcleo do Sol}

No modelo que adotamos aqui [47], os Simpzillas se aniquilam gerando dois quarks ou dois gluons, cada um com energia equivalente à massa do Simpzilla. Estes quarks e gluons se fragmentam em jatos hadrônicos [48]. Entre estas partículas, o quark top decai gerando uma cadeia que produz neutrinos. Seu tempo de vida é pequeno $\left(\sim 10^{-25} s\right)$, e ele decai $\sim 100 \%$ das vezes em um boson $W$ mais um quark bottom. O $W$ também tem um tempo de vida pequeno, e decai em um par $l \nu_{l}$ (lepton mais o neutrino correspondente), com igual probabilidade de cerca de $10 \%$ para cada sabor. 


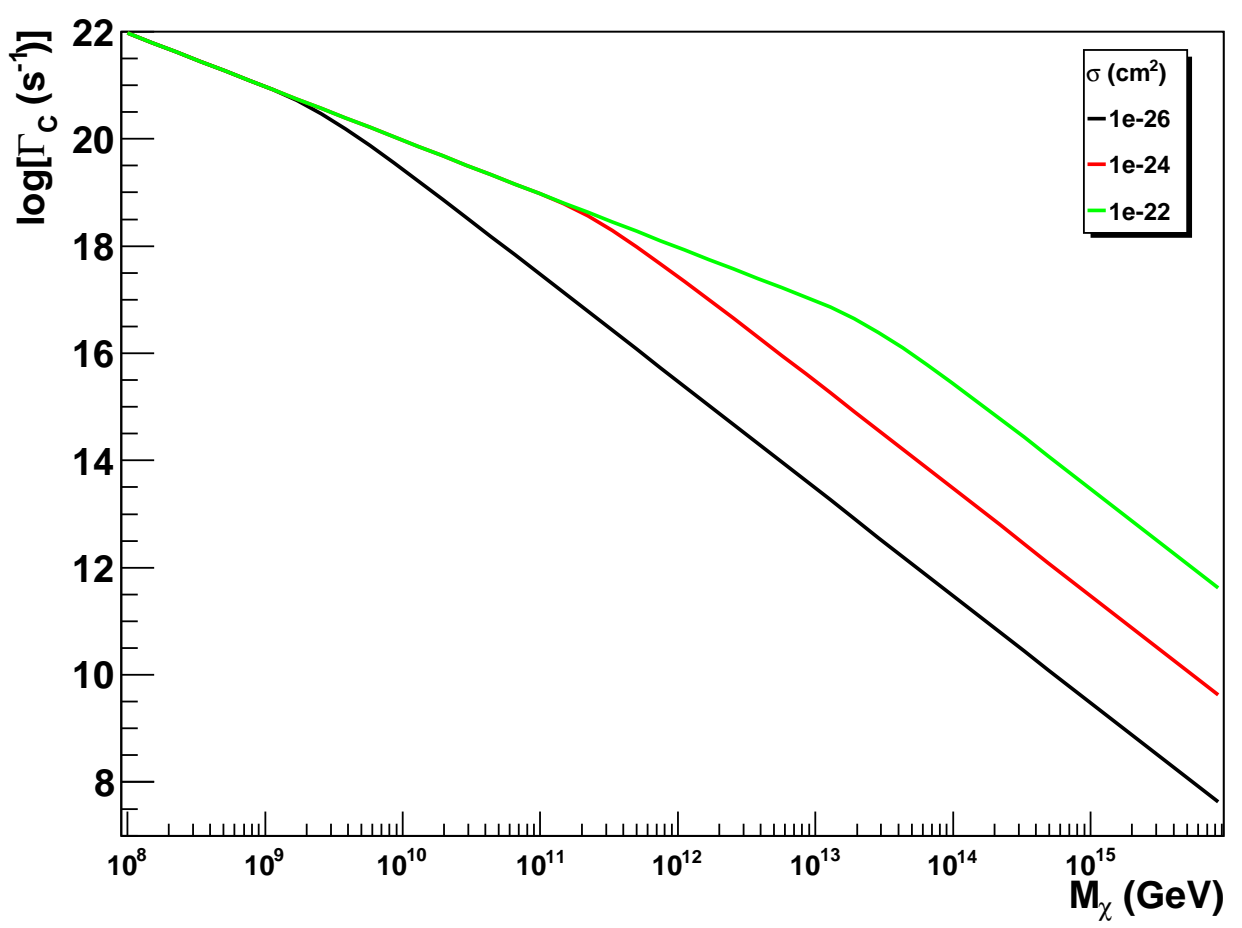

Figura 4.1: Taxa de captura obtida para diferentes combinações de massa e seção de choque do Simpzilla. Parâmetros astrofísicos utilizados: $\rho_{\chi}=0.3 \mathrm{GeV} / \mathrm{cm}^{3}$ e $u_{0}=240 \mathrm{~km} / \mathrm{s}$.

Apesar de outras partículas geradas na aniquilação de $\chi$ 's também gerarem cadeias que terminam na produção de neutrinos (como no caso do quark b), nos preocupamos apenas com um canal $(t \rightarrow W \rightarrow \nu$ ), que gera neutrinos cujo espectro resultante, para cada sabor, pode ser ajustado por [47]

$$
\frac{d N}{d E_{\nu}} \propto \frac{E_{\nu}+m_{W}}{\sqrt{\left(E_{\nu}+m_{t}\right)\left[\left(E_{\nu}+m_{t}\right)^{2}-m_{t}^{2}\right]\left[\left(E_{\nu}+m_{W}\right)^{2}-m_{W}^{2}\right]}},
$$

com $m_{W}$ e $m_{t}$ sendo as massas do boson $W$ e do quark top respectivamente. Como estamos interessados em construir uma região de exclusão de parâmetros, o fato de considerarmos apenas este canal, sem acrescentar outros, resulta em uma análise menos restritiva.

Este espectro de neutrinos no núcleo do Sol é mostrado na Figura 4.2. As energias típicas são muito menores que as massas possíveis para o Simpzilla, dado que a energia disponível é compartilhada pelo grande número de partículas criadas. 


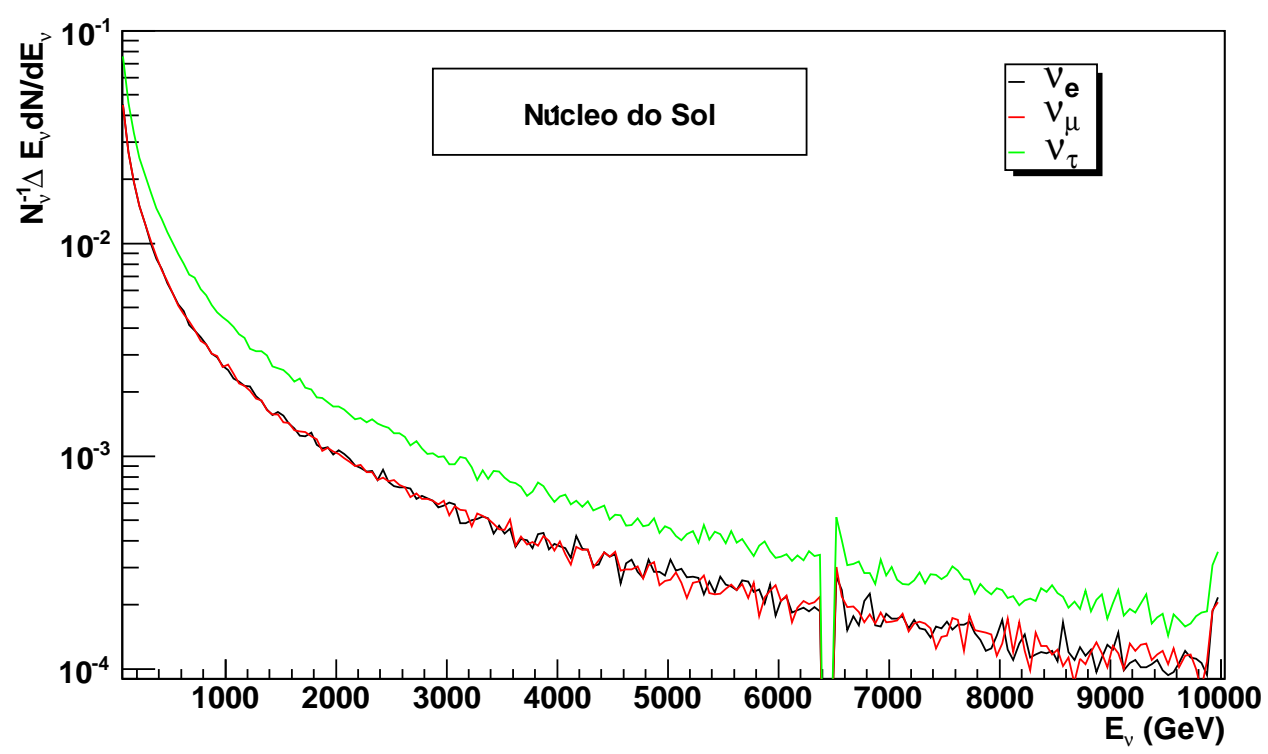

Figura 4.2: Espectro de neutrinos no núcleo do Sol, obtido com o WIMPSIM alterado, normalizado pelo número total $N_{\nu}$ de neutrinos produzidos. O decaimento do $W$ produz um lepton mais o neutrino correspondente com probabilidades iguais para os diferentes sabores. O que faz o número de $\nu_{\tau}$ 's ser maior é que o $\tau$ produzido automaticamente decai gerando outro $\nu_{\tau}$ (e mais um $\nu_{e}$ ou $\nu_{\mu}$ com $18 \%$ de chance para cada), o que não ocorre com o elétron ou com o $\mu$, que rapidamente perdem toda a energia e são absorvidos. Assim o número de $\nu_{\tau}$ 's representa cerca de $20 \%$ do número de $W$ 's gerados, contra $11,8 \%$ de $\nu_{\mu}$ 's e $11,8 \%$ de $\nu_{e}^{\prime}$ 's.

\subsection{Propagação dos neutrinos}

Como último ingrediente no cálculo do fluxo de neutrinos na Terra (equação 4.1), precisamos determinar o espectro de energia $\frac{d N}{d E}$ dos neutrinos emergentes do Sol, levando em conta as alterações desse espectro do núcleo até a superfície, e depois até o detector. Estas alterações ocorrem devido às interações e perda de energia dos neutrinos no Sol e na Terra, além das oscilações entre os diferentes sabores. Para calcular essas alterações, utilizamos o programa de simulação Monte-Carlo WIMPSIM [8].

Este programa contabiliza as aniquilações de WIMPs no núcleo do Sol e simula a propagação dos neutrinos resultantes até o detector. Ele é dividido em duas partes: WimpAnn e WimpEvent. A primeira determina o número e o espectro de energia de neutrinos produzidos no núcleo do Sol a partir de algum canal de aniquilação escolhido. Simula então a propagação dos neutrinos no interior do Sol, incluindo as interações com os nucleons, bem como as oscilações entre os diferentes sabores. As trajetórias são simuladas até a superfície e depois até a distância de 1 Unidade Astronômica (U. A.), ou seja, logo 
antes de entrar na Terra. Para realizar os cálculos no interior do Sol, o programa utiliza o Standard Solar Model [49], que fornece informações sobre as abundâncias e densidades dos principais elementos como função da distância ao centro.

A segunda parte (WimpEvent) lê os dados gerados pela primeira, simula a propagação dos neutrinos dentro da Terra até o detector, a uma dada latitude $\left(-90^{\circ}\right.$ no caso do IceCube), e integra a taxa de eventos esperada num certo intervalo de tempo. O programa inclui em seus cálculos a excentricidade da órbita da Terra e a rotação em torno de seu eixo. Isso permite determinar o caminho percorrido dentro da Terra até o detector, onde se incluem informações sobre o perfil de densidade da Terra. O modelo adotado para este perfil é o de [50], em que a Terra é dividida basicamente em duas regiões: núcleo e manto. Além disso, o programa assume que o periélio e o solstício de inverno (do hemisfério Norte) ocorrem no mesmo dia, no Ano Novo.

Como este programa foi feito tendo em vista aniquilações de WIMP's, tivemos que modificá-lo, dado que estamos interessados nas aniquilações de Simpzillas. Alteramos o WimpAnn, modificando o espectro de neutrinos no núcleo do Sol conforme a equação 4.6. A partir daí, o programa continua propagando estes neutrinos até o detector como em sua versão original, em que são levadas em conta suas interações com os nucleons e suas oscilações entre os diferentes sabores.

As interações com os nucleons são de Corrente Neutra ou de Corrente Carregada. Nas primeiras, o neutrino perde energia mas seu sabor é conservado. Nas interações de Corrente Carregada, o neutrino é absorvido e dá origem a um lepton carregado de mesmo sabor $\left(\nu_{e} \rightarrow e\right.$ ou $\nu_{\mu} \rightarrow \mu$ ou $\left.\nu_{\tau} \rightarrow \tau\right)$. Depois disso, durante a propagação no interior do Sol, os comportamentos destes leptons são bastante diferentes entre si.

No caso do $\nu_{\tau}$, o $\tau$ gerado na interação sempre decai dando origem a outro $\nu_{\tau}$ (além de um $\nu_{\mu}$ ou um $\nu_{e}$, com $18 \%$ de chance para cada um). Isso ocorre porque a vida média do $\tau$ é pequena, cerca de $10^{-13} s$, e ele decai antes de ser absorvido. Esse processo é chamado de regeneração do $\nu_{\tau}$. O mesmo não ocorre com o $\nu_{\mu}$ ou $\nu_{e}$, já que seus leptons correspondentes perdem toda energia antes de decair (a vida média do $\mu$ é de cerca de $\approx 10^{-6} s$ e o elétron é estável).

Para se ter ideia das probabilidades relativas de interação de Corrente Neutra e Carregada, mostramos na Figura 4.3 as respectivas seções de choque para neutrinos de altas energias obtidas por [45].

\section{Oscilações dos neutrinos}

As oscilações entre os diferentes sabores dos neutrinos $\left(\nu_{e}, \nu_{\mu}\right.$ ou $\left.\nu_{\tau}\right)$ ocorrem devido a que seus auto-estados de massa não são auto-estados de sabor, ou seja, a massa não pode ser diagonalizada simultaneamente com o sabor. Isso implica numa oscilação, com 


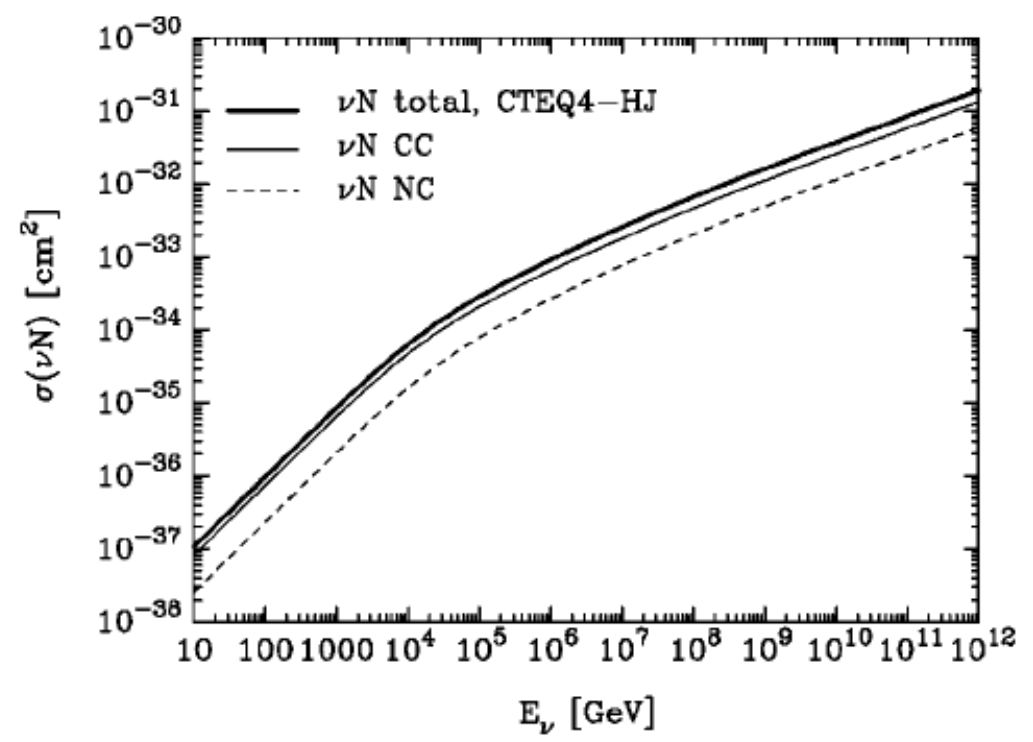

Figura 4.3: Seções de choque neutrino-nucleon para interações de Corrente Neutra (NC) e Corrente Carregada (CC) - extraído de [45].

probabilidades bem definidas, entre os três sabores. Essas probabilidades podem ser obtidas a partir da chamada leptonic mixing matrix, cujos parâmetros são determinados experimentalmente [46], e indicam que as oscilações entre $\nu_{\mu}$ e $\nu_{\tau}$ são bem mais intensas que aquelas entre estes e o $\nu_{e}$.

As oscilações devem ser consideradas na propagação dos neutrinos pois, apesar de não alterarem o número total destas partículas, alteram os espectros de cada um dos sabores.

A Figura 4.4 mostra o espectro dos três sabores na superfície do Sol, ilustrando o efeito destas oscilações, para cujos parâmetros utilizamos os valores padrões [46].

\subsubsection{Espectro de $\nu_{\mu}$ 's}

A partir daqui, nos concentramos no espectro de $\nu_{\mu}$ 's, dado que os resultados publicados pelo IceCube se referem a este sabor. A Figura 4.5 mostra o espectro dos $\nu_{\mu}$ 's em três regiões diferentes: no núcleo do Sol, em sua superfície e a 1 U. A. de distância. Devido às interações de Corrente Neutra, um grande número de neutrinos perde energia no interior do Sol e, do núcleo até a superfície, o espectro se desloca para valores menores de energia. As interações de Corrente Carregada promovem uma grande diminuição do número de $\nu_{\mu}$ 's, o que se percebe verificando que a área embaixo dos espectros na superfície e a 1 U.A. é bem menor que área do espectro no núcleo. Mais precisamente, o número de $\nu_{\mu}$ 's que chegam à superfície representam cerca de $40 \%$ do número de $\nu_{\mu}$ 's produzidos no núcleo. Da superfície do Sol até a Terra o espectro praticamente não muda, as oscilações 


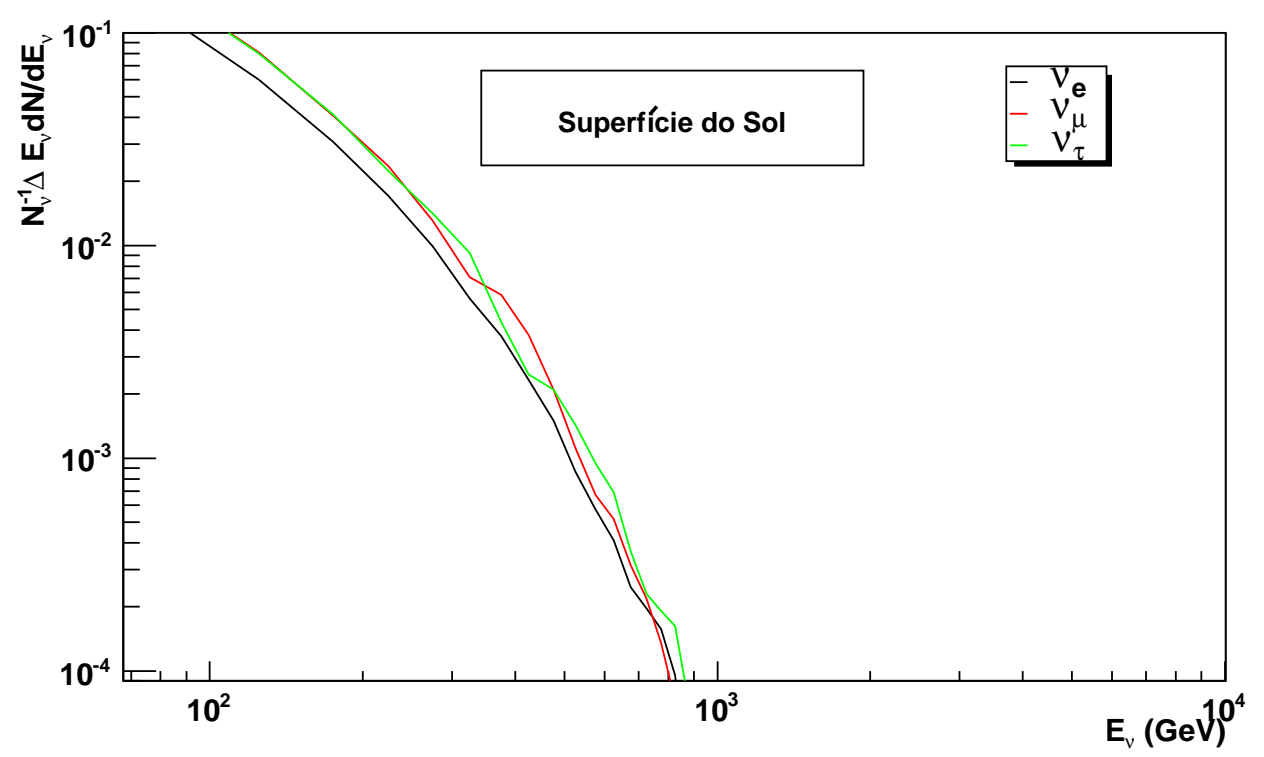

Figura 4.4: Espectro de neutrinos na superfície do Sol, obtido com o WIMPSIM alterado, normalizado pelo número total $N_{\nu}$ de neutrinos nesta posição. A escala é diferente da adotada anteriormente apenas para evidenciar o efeito das oscilações.

no vácuo sendo pouco importantes.

Ao propagar os neutrinos, desde o ponto de incidência na Terra até o detector, e simular o sinal esperado, é necessário indicar sua latitude e a época do ano durante a qual os dados são tomados. Tendo em vista que, para diminuir o fluxo de $\mu$ 's atmosféricos, precisamos selecionar $\nu_{\mu}$ 's com ângulos de incidência $\varphi>90^{\circ}$, rodamos a segunda parte (WimpEvent) do programa simulando dados obtidos entre Março e Setembro, época do ano em que o Sol está abaixo do horizonte no Pólo Sul. 


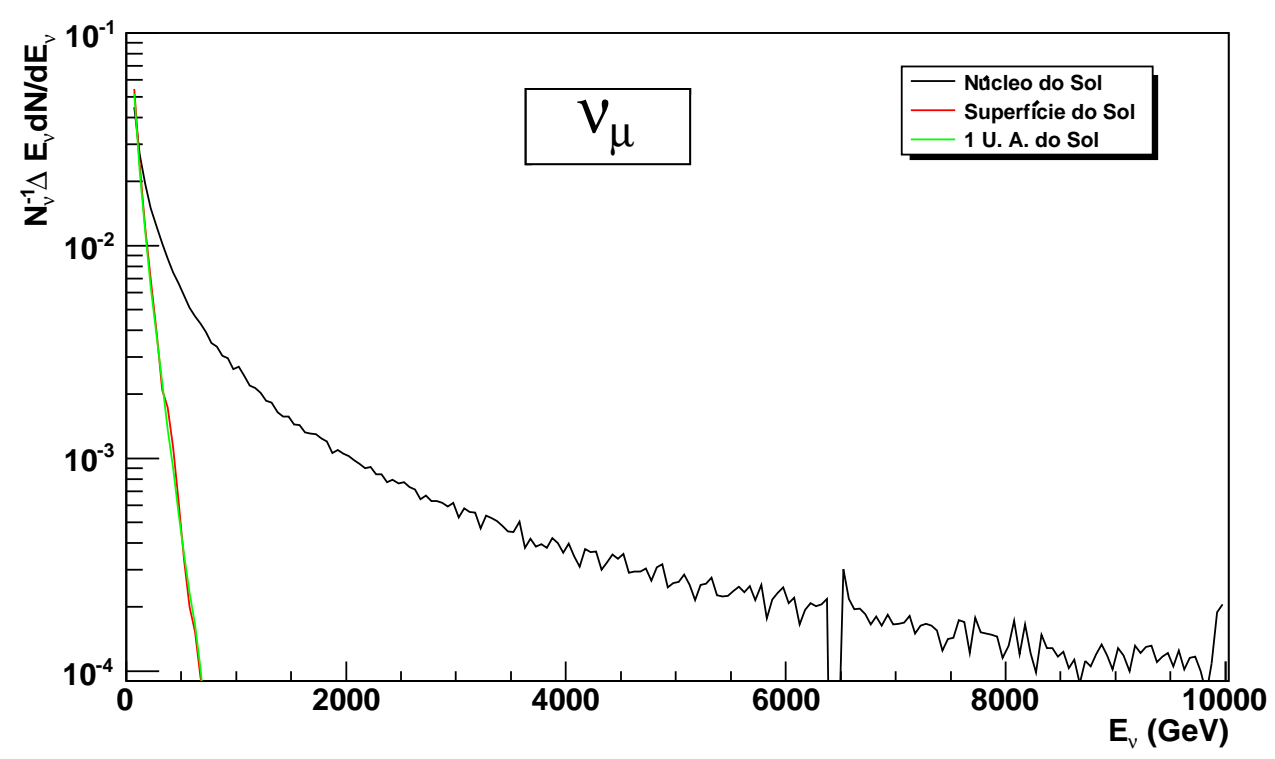

Figura 4.5: Espectro do $\nu_{\mu}$ em três posições diferentes: no núcleo do Sol, em sua superfície e a 1 U. A. de distância, normalizado pelo número total $N_{\nu}$ de neutrinos (dos três sabores) produzidos no núcleo. 


\section{Capítulo 5}

\section{Comparação com os dados e conclusões}

\subsection{Previsão do número de eventos}

De posse do espectro $\frac{d N}{d E_{\nu}}$ de neutrinos que chegam ao detector, o número $N$ de eventos esperado em um experimento de área efetiva $A_{e f e t}$, tomando dados durante um intervalo de tempo $t$, é dado por

$$
N\left(M_{\chi}, \sigma\right)=\Gamma_{A} \cdot N_{t} \cdot B_{F} \cdot t \int \frac{d N_{\nu}}{d E} A_{e f e t} d E,
$$

onde $N_{t}$ é o número de tops gerados em cada aniquilação [47]. Lembrando que o top decai sempre em $\mathrm{W}, B_{F}=0.326$ é a razão de ramificação para a produção de neutrinos a partir do decaimento do W.

A área efetiva, como definida pelo experimento IceCube [43], incorpora as informações sobre as dimensões da experiência e sobre a eficiência dos detectores. Além disso, inclui a probabilidade de haver uma interação de Corrente Carregada do $\nu_{\mu}$ gerando o $\mu$ e leva em conta a perda de energia deste último desde o ponto onde ele é criado até sua passagem pelo detector [3]. Isso define uma distância máxima, dependente da energia do $\mu$, que o ponto de criação deve ter para que o $\mu$ não perca toda sua energia antes de chegar ao detector.

A fase em que o IceCube tomou dados com os primeiros 22 cabos instalados durou 104.3 dias entre Junho e Setembro de 2007. A colaboração IceCube analisou estes dados em busca de neutralinos [43] e de Lightest Kaluza-Klein Particles (LKP) [44]. Nestas análises sua área efetiva, conforme definido acima, foi parametrizada. Apesar desta se basear em aniquilações de candidatos bem mais leves que o Simpzilla, ela pode ser utilizada no nosso caso, já que a forma dos espectros de energia dos neutrinos resultantes de 
aniquilações é parecida [3]. Isto se deve ao fato de que a energia liberada na aniquilação dos Simpzillas é compartilhada por um grande número de partículas. A Figura 5.1 mostra essa área efetiva parametrizada.

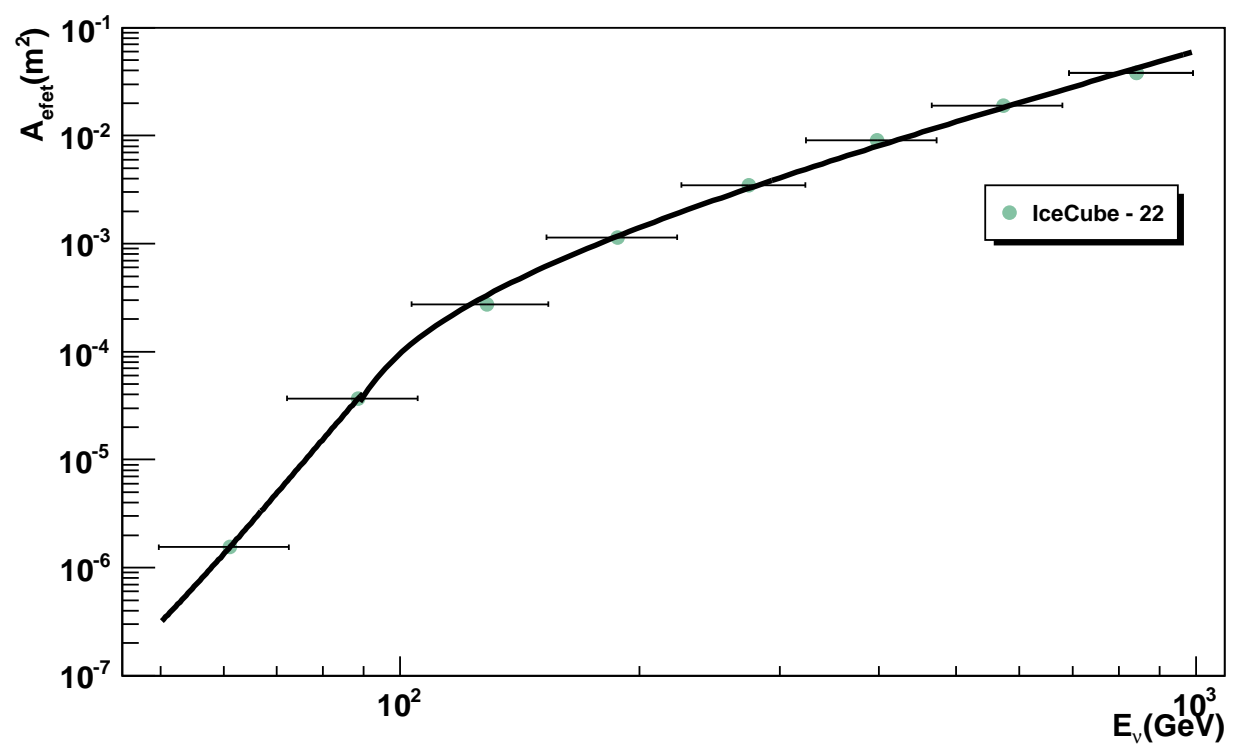

Figura 5.1: Área Efetiva parametrizada para a configuração do IceCube com 22 cabos $[43,44]$.

Utilizando todos esses ingredientes, calculamos o número de eventos previsto (expressão 5.1) para o período de 104.3 dias de tomada de dados do IceCube. O resultado é mostrado na Figura 5.2 para algumas seções de choque Simpzilla-nucleon. O formato destas curvas reproduz basicamente o formato da taxa de captura (Figura 4.1), com a qual se relaciona a taxa de aniquilação $\left(\Gamma_{A}=\frac{1}{2} \Gamma_{C}\right)$. Este resultado é compatível com o encontrado em [3].

\subsection{Comparação com os dados do IceCube}

A Figura 5.3 mostra a distribuição angular, próximo à direção do Sol, dos dados medidos pelo IceCube, assim como o fundo esperado (simulado). Este fundo é constituído de $\nu_{\mu}$ 's atmosféricos. A figura 5.3 também mostra o sinal simulado devido à aniquilação de WIMP's, mas não utilizamos esta informação. Comparando o fundo simulado (em vermelho) com os dados medidos na direção do Sol $(\cos \Psi=1)$, percebemos que não há um excesso de neutrinos nesta direção. Ao contrário, o número de eventos medido é até menor que o fundo esperado, e essa diferença pode ser atribuída à flutuação estatística dos dados. 


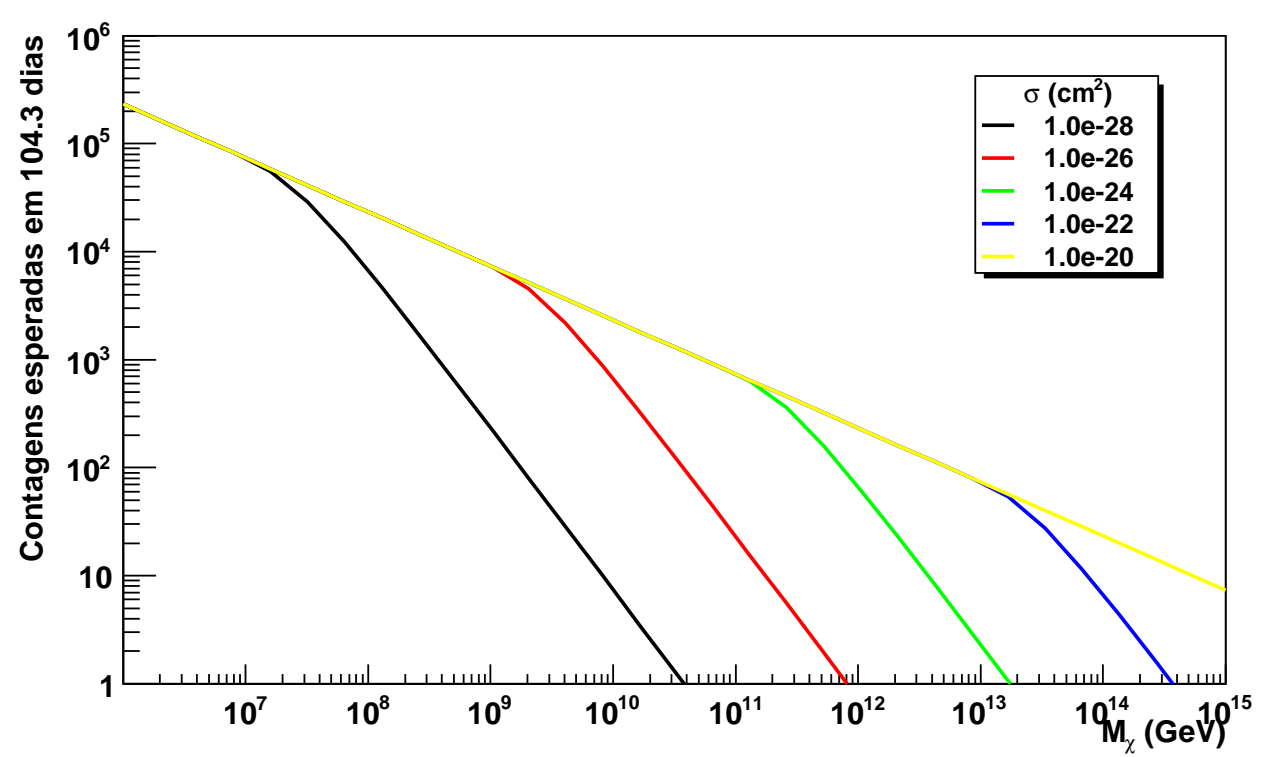

Figura 5.2: Número de eventos previsto, para o período de 104.3 de tomada de dados do IceCube, como função da massa do Simpzilla, para algumas seções de choque Simpzillanucleon.

A partir do número de eventos medidos e do fundo esperado na direção do Sol, calculamos um limite superior para o número de eventos atribuíveis às aniquilações de Simpzillas. Para isso utilizamos o método de Rolke, López e Conrad [51], supondo um fundo gaussiano com $15 \%$ de incerteza e uma eficiência de 100\%, já que a eficiência de fato entra no cálculo da área efetiva. Com 18 contagens esperadas para o fundo e 13 eventos medidos, obtivemos um limite superior de 3 eventos devidos às aniquilações de Simpzillas, com um nível de confiança de $90 \%$.

Isso nos permitiu verificar quais combinações entre a massa e a seção de choque do Simpzilla (Figura 5.2) previa um número de eventos maior que este limite superior. Estas combinações foram então consideradas excluídas. Essa zona de exclusão, que é essencialmente a mesma que a obtida por [3], é mostrada na Figura 5.4, superposta às zonas de exclusão obtidas previamente por outras análises. Podemos perceber que as lacunas deixadas anteriormente foram de fato incorporadas à zona de exclusão.

Na sequência, discutiremos o significado destes resultados e alguns aspectos do modo como foram obtidos, analisando as possíveis fontes de erro envolvidas. 


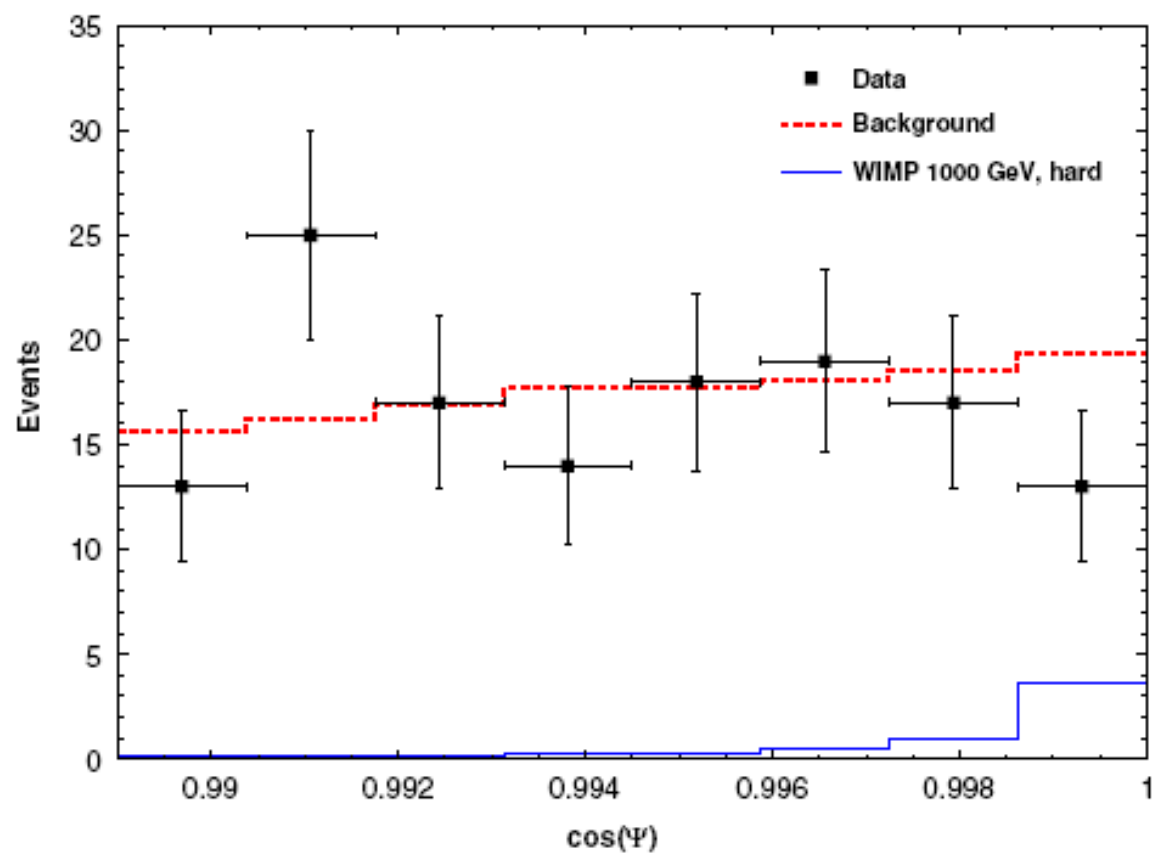

Figura 5.3: Número de eventos medido como função do ângulo $\Psi$ entre a direção reconstruída do $\nu_{\mu}$ e a direção do Sol. Também são mostrados, em vermelho, o fundo esperado de $\nu_{\mu}$ 's, através de simulação realizada pelo IceCube, e em azul o número de eventos esperados devido às aniquilações de neutralinos. Extraído de [43].

\subsection{Discussão dos resultados}

Antes de analisar as possíveis fontes de erro nos resultados, devemos ter em mente que estamos interessados na zona de exclusão massa versus seção de choque. Desta forma, concentramos nossa atenção nos erros que diminuem a região excluída pela nossa análise.

É também importante ressaltar que esta análise não inclui todos os canais de produção de neutrinos (como por exemplo os neutrinos provenientes do decaimento dos quarks b). Apenas o canal do quark top já permite excluir a região previamente não testada. Nesse sentido, nossa análise é conservadora.

Na taxa de captura, que determina diretamente a taxa de aniquilação, as principais fontes de incerteza são de origem astrofísica. Vamos então avaliar o papel que estes parâmetros exercem, estudando como suas incertezas afetam a zona de exclusão.

\subsubsection{Incerteza na densidade local}

A densidade local de ME, $\rho_{\chi}$, por exemplo, pode ser obtida da curva de rotação da Galáxia ou através de simulações. Adotamos o valor padrão $\rho_{\chi}=0,3 \mathrm{GeV} / \mathrm{cm}^{3}$. 


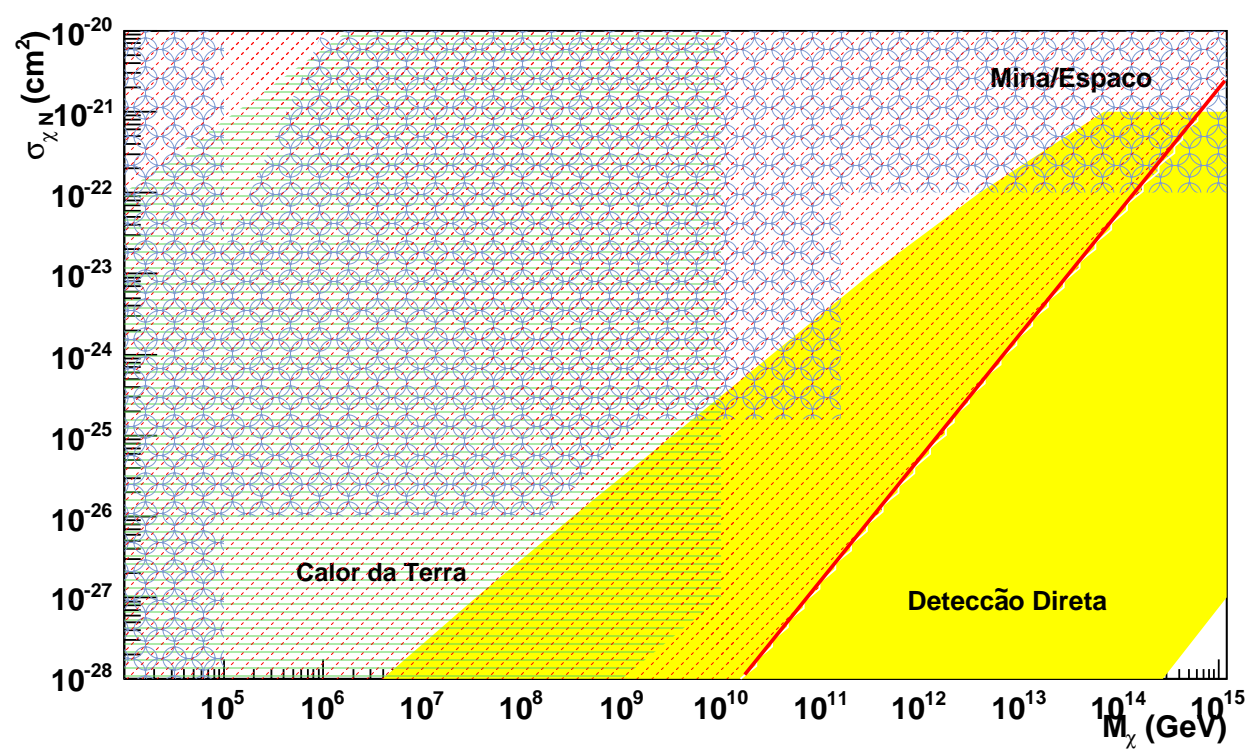

Figura 5.4: Seção de choque Simpzilla-nucleon versus massa do Simpzilla. Toda a região acima e à esquerda da linha vermelha está excluída com nível de confiança (N.C.) de $90 \%$, pela análise descrita aqui. Esta zona de exclusão está superposta às obtidas pelas análises anteriores, mostradas na Figura 1.1.

Há resultados recentes [53], porém, que indicam que esta grandeza pode ser um pouco maior do que isso: $\rho_{\chi}=0,43 \pm 0,15 \mathrm{GeV} / \mathrm{cm}^{3}$, enquanto outro resultado recentemente obtido [54] indica que $\rho_{\chi}=0,3 \pm 0,1 \mathrm{GeV} / \mathrm{cm}^{3}$. Uma densidade local maior aumenta a taxa de aniquilação e consequentemente a zona de exclusão. Uma densidade local menor, por outro lado, diminui o número previsto de eventos, e isso diminui a zona de exclusão. A Figura 5.5 mostra o resultado da variação da densidade local entre os limites inferior $\left(0,2 \mathrm{GeV} / \mathrm{cm}^{3}\right)$ e superior $\left(0,58 \mathrm{GeV} / \mathrm{cm}^{3}\right)$ permitidos pelos valores acima.

Desta forma, mesmo adotando um valor menor para a densidade local de ME, as regiões anteriormente permitidas ainda são excluídas pela análise dos dados do IceCube, e percebemos que o impacto da incerteza deste parâmetro sobre a análise é pequeno.

\subsubsection{Incerteza na velocidade}

Outro parâmetro importante da taxa de captura é a velocidade mais provável dos $\chi$ 's no halo, para a qual utilizamos $u_{0}=240 \mathrm{~km} / \mathrm{s}$. Supondo o halo galático isotrópico e esfericamente simétrico, Drukier, Freese e Spergel [55] mostraram que a dispersão de velocidades dos $\chi$ 's no halo, $\left\langle u^{2}\right\rangle$, se relaciona com a velocidade de rotação da Galáxia na posição do Sol, $v_{c}$, como $\left\langle u^{2}\right\rangle=\frac{3}{2} v_{c}^{2}$. A dispersão (no caso de Maxwell-Boltzmann de média nula) se relaciona com a velocidade mais provável como $\left\langle u^{2}\right\rangle=\frac{3}{2} u_{0}^{2}$, de onde 


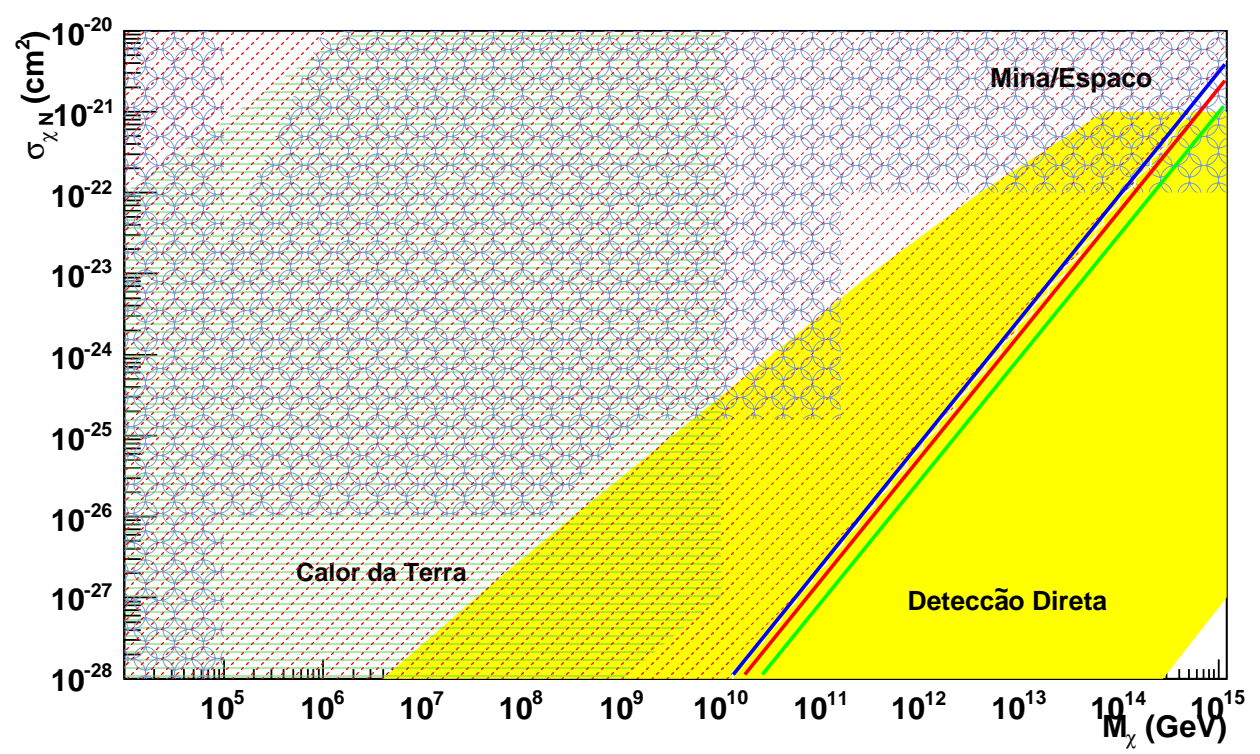

Figura 5.5: Zona de exclusão (N.C. de 90\%) do Simpzilla. Fixado $u_{0}=240 \mathrm{~km} / \mathrm{s}$, as linhas azul, vermelha e verde correspondem aos limites superiores da zona de exclusão com os respectivos valores de $\rho_{\chi}: 0.2 \mathrm{GeV} / \mathrm{cm}^{3}, 0.3 \mathrm{GeV} / \mathrm{cm}^{3}$ e $0.58 \mathrm{GeV} / \mathrm{cm}^{3}$, onde $0.3 \mathrm{GeV} / \mathrm{cm}^{3}$ é o valor adotado em nosso trabalho.

concluímos que $u_{0}=v_{c}$. Portanto, uma boa estimativa para $u_{0}$ é a velocidade $v_{c}$ com que o Sol se movimenta com relação ao centro galático. Dadas as incertezas envolvidas nesta grandeza, podemos dizer que ela se encontra no intervalo $200 \mathrm{~km} / \mathrm{s}<v_{c}<250 \mathrm{~km} / \mathrm{s}$ [52]. Com um valor pequeno de $u_{0}$ os $\chi$ 's se movem com energia cinética menor em média, por isso são mais facilmente capturados, o que aumenta o número previsto de eventos e isso promove um aumento da zona de exclusão. Um grande valor de $u_{0}$, por sua vez, diminui a zona de exclusão. A Figura 5.6 mostra como se comporta este gráfico quando variamos $u_{0}$ no intervalo acima. Mais uma vez, a variação deste parâmetro não interfere em nossos resultados.

Além de determinar a velocidade mais provável dos $\chi$ 's no halo, $u_{0}$, o movimento do Sol ao redor do centro galático altera a forma da distribuição de velocidades, efeito que até aqui havíamos desprezado (página 32). Se, para um observador parado com relação ao halo de ME, a distribuição de velocidades é $f(u)=4 \frac{n_{\chi}}{\sqrt{\pi u_{0}^{2}}}\left(\frac{u}{u_{0}}\right)^{2} e^{-\left(\frac{u}{u_{0}}\right)^{2}}$, é possível mostrar que, para um observador com velocidade $v_{c}=u_{0}$ a distribuição é dada por

$$
g(u)=\frac{n_{\chi}}{\sqrt{\pi u_{0}^{2}}}\left(\frac{u}{u_{0}}\right)\left[e^{-\left(\frac{u}{u_{0}}-1\right)^{2}}-e^{-\left(\frac{u}{u_{0}}+1\right)^{2}}\right] .
$$

Este movimento do Sol faz com que a taxa de captura diminua, já que no seu referencial 


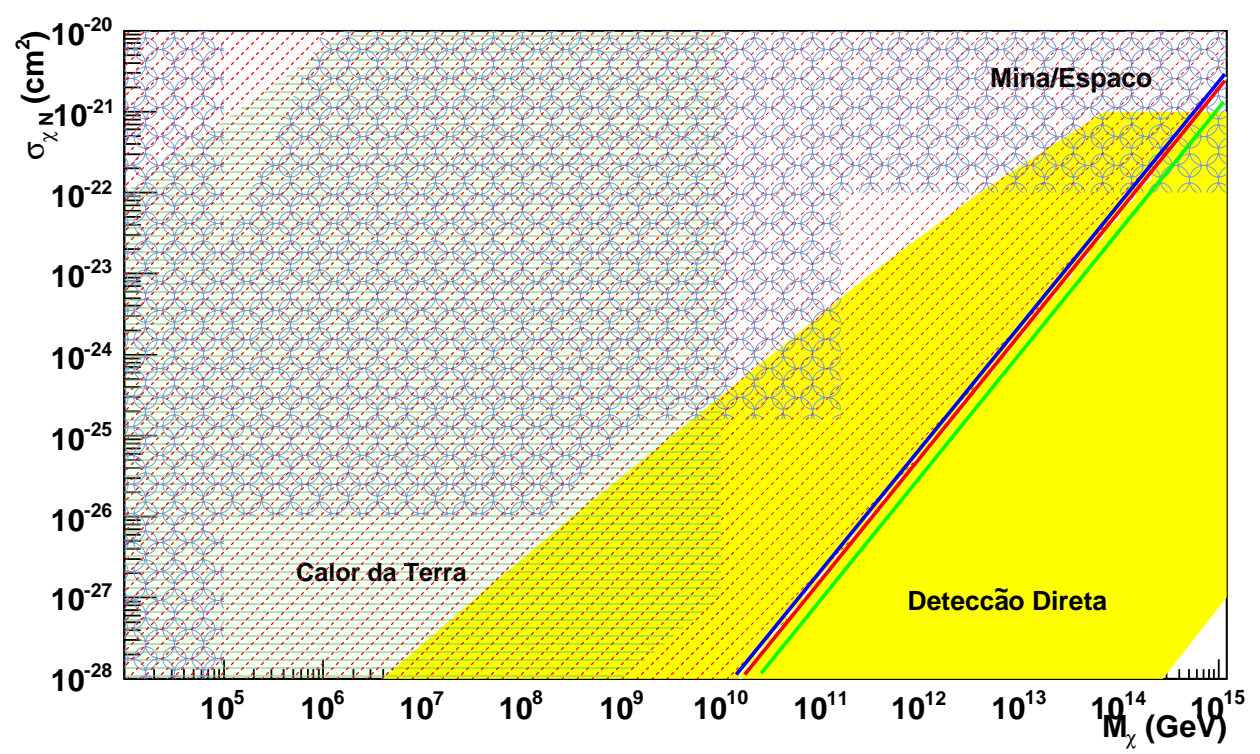

Figura 5.6: Zona de exclusão (N.C. de 90\%) do Simpzilla. Fixado $\rho_{\chi}=0.3 \mathrm{GeV} / \mathrm{cm}^{3}$, as linhas azul, vermelha e verde correspondem aos limites superiores da zona de exclusão com os respectivos valores de $u_{0}: 250 \mathrm{~km} / \mathrm{s}, 240 \mathrm{~km} / \mathrm{s}$ e $200 \mathrm{~km} / \mathrm{s}$.

a energia cinética dos $\chi$ 's fica maior em média [41]. Isso propicia uma diminuição da zona de exclusão, como pode ser visto na Figura 5.7, obtida com a nova distribuição de velocidades. Apesar deste efeito ser considerável, novamente não modifica nossas conclusões.

\subsubsection{Velocidade de escape da Galáxia}

Outro efeito que não havíamos considerado até aqui é o corte na distribuição de velocidades produzido pela velocidade de escape da Galáxia nos arredores do Sol, $V_{\text {esc }}$. Este parâmetro pode ser obtido estudando-se o movimento de estrelas de alta velocidade nos arredores do Sistema Solar. Medidas recentes [56] indicam que a velocidade de escape local deve estar no intervalo $498 \mathrm{~km} / \mathrm{s}<V_{\text {esc }}<608 \mathrm{~km} / \mathrm{s}$.

Assim, ao determinar a taxa de captura - expressão 4.5 - a integral em $d u$ deve ser calculada não mais até $u_{\star}$, mas até o menor valor entre $u_{\star}$ e $V_{\text {esc }}$. Como isso representa uma restrição no critério de captura, o sinal esperado deve ser menor, assim como a zona de exclusão. Considerando-se este efeito, a zona de exclusão obtida por nós resultou indistinguível das anteriores, independente do valor de $V_{e s c}$ no intervalo acima, ou seja, o efeito é muito pequeno. Isso deve-se ao fato de que a contribuição de partículas com alta velocidade à taxa de captura é desprezível.

Como última avaliação dos possíveis erros cometidos, construímos a "pior" zona de 


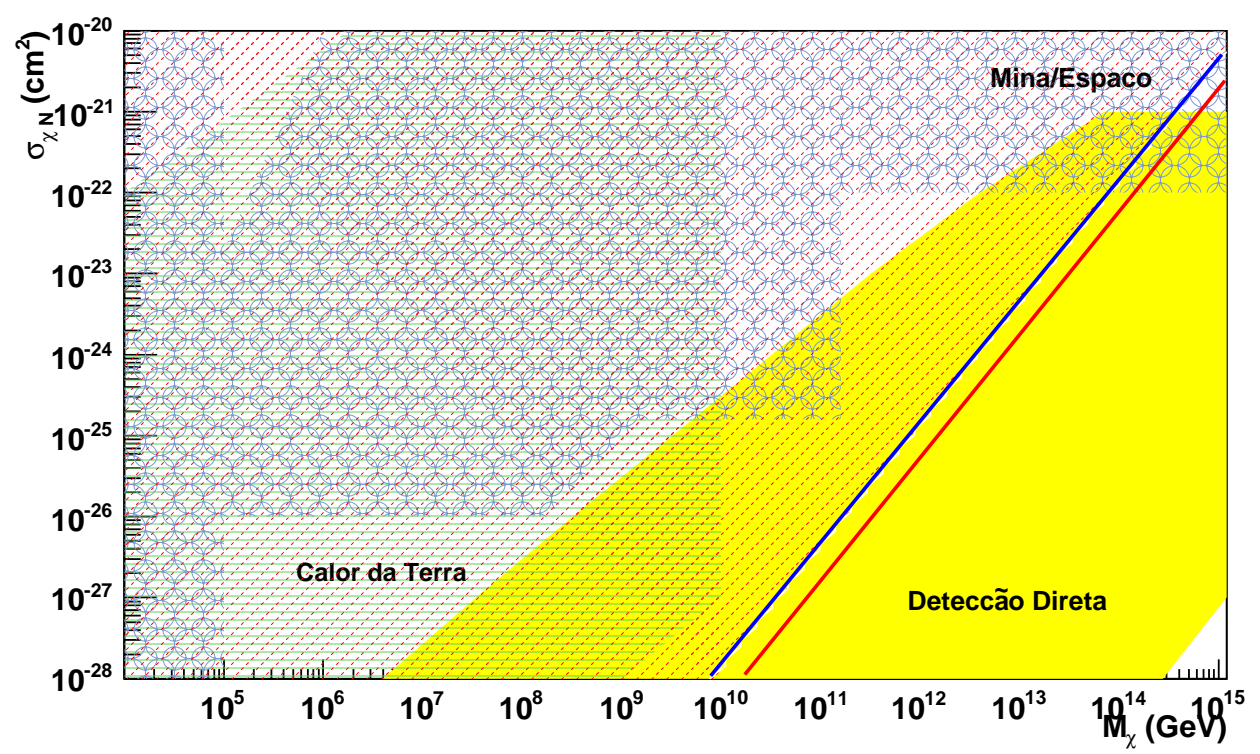

Figura 5.7: Zona de exclusão (N.C. de 90\%) do Simpzilla. Parâmetros astrofísicos utilizados: $\rho_{\chi}=0.3 \mathrm{GeV} / \mathrm{cm}^{3}$ e $u_{0}=240 \mathrm{~km} / \mathrm{s}$, agora levando em conta a alteração na distribuição de velocidades produzida pelo movimento do Sol. As linhas azul e vermelha representam os limites superiores da zona de exclusão utilizando-se respectivamente as distribuições de velocidade com e sem o movimento do Sol.

exclusão possível, ou seja, utilizando todos os parâmetros listados acima com os valores permitidos que mais a diminuam. Isso é mostrado na Figura 5.8, onde percebemos que mesmo nesta situação nossas conclusões permanecem válidas.

\subsection{Conclusões}

Os dados publicados pelo IceCube mostram que o número de eventos vindos da direção do Sol é completamente compatível com o fundo esperado no período. Com isso, o número de eventos atribuíveis às aniquilações de $\chi$ 's no núcleo do Sol é pequeno, o que possibilitou a exclusão de grande parte do espaço de fases do Simpzilla. A zona de exclusão obtida é mostrada na Figura 5.4, em que percebemos que as lacunas deixadas pelas análises anteriores foram excluídas.

A grande superposição entre a nova zona de exclusão e as anteriores confirma, de forma independente, os resultados anteriores. Também é particularmente interessante no que se refere às diferentes componentes da seção de choque [3]. A esta podem contribuir uma componente dependente de spin e uma componente independente de spin. As análises anteriores, ou por envolver a captura de Simpzillas pela Terra, cujos principais elementos 


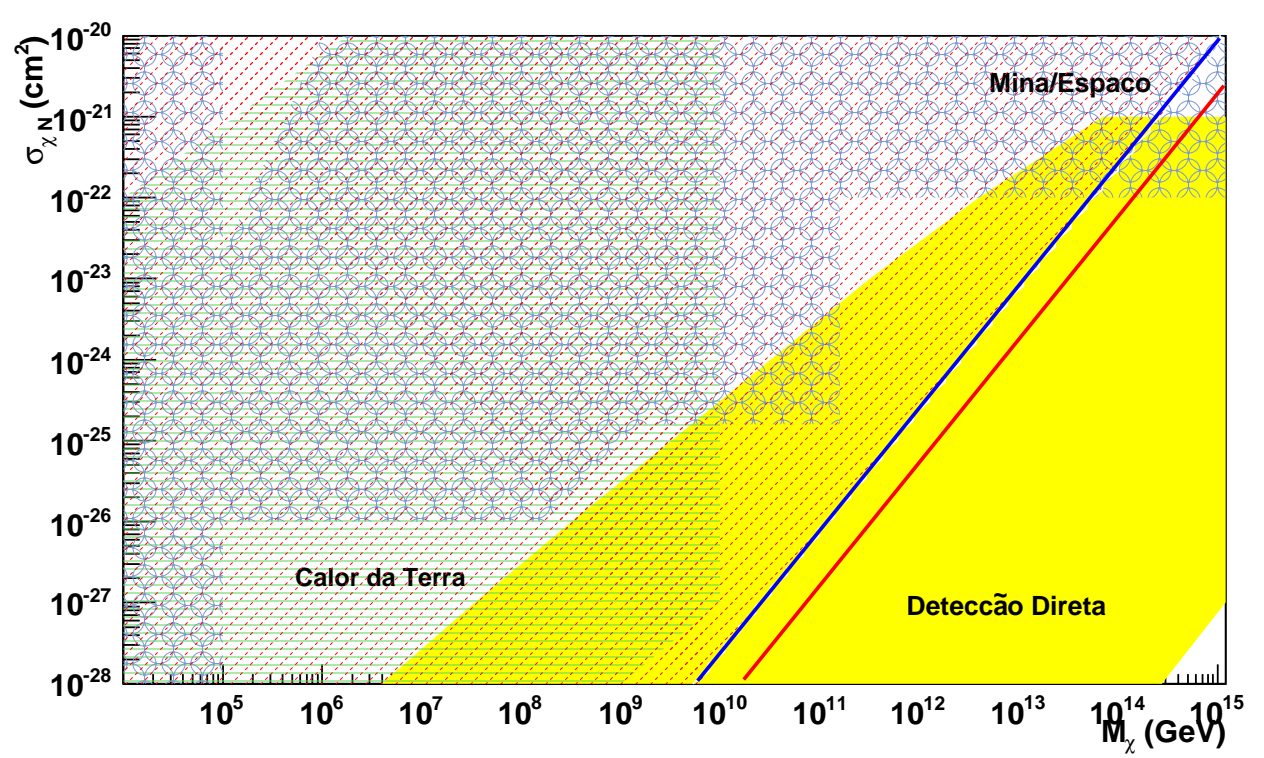

Figura 5.8: "Pior" zona de exclusão (N.C. de 90\%) do Simpzilla possível, obtida com os valores permitidos para os parâmetros astrofísicos que a minimizam. Os valores utilizados são: $\rho_{\chi}=0.2 \mathrm{GeV} / \mathrm{cm}^{3}$ e $u_{0}=250 \mathrm{~km} / \mathrm{s}$, e levando em conta a alteração na distribuição de velocidades produzida pelo movimento do Sol. A linha azul indica esse limite inferior e a vermelha, como anteriormente, o limite obtido na Figura 5.4.

são $F e, S i, O$ e $M g$, ou pelos elementos envolvidos na detecção, privilegiam a componente independente de spin. Já a análise desenvolvida aqui tem como ingrediente a captura de Simpzillas pelo Sol, que é basicamente composto de prótons, ou seja, privilegia a componente dependente de spin. Assim, a superposição das zonas de exclusão representa uma complementaridade importante entre estas análises.

Por fim, avaliamos como as incertezas em alguns parâmetros astrofísicos e alguns refinamentos do modelo afetam a zona de exclusão obtida. Concluímos que o modelo é robusto com relação a estes parâmetros, ou seja, estas incertezas resultam em modificações pequenas da zona de exclusão (a maior delas é aquela devida à inclusão do movimento do Sol ao redor do centro galático), sendo irrelevantes em termos das zonas previamente não excluídas.

Com isso concluímos que partículas massivas e fortemente interagentes não compõem a matéria escura. 


\section{Apêndice A}

\section{Curvas de Rotação em detalhes}

Uma análise mais detalhada das curvas de rotação deve levar em conta que as galáxias não têm simetria esférica, e por isso seu potencial gravitacional não é da forma $\Phi=\frac{G M}{r}$, e é preciso considerar a forma como a massa é distribuída ao longo do plano. Essa massa pode ser dividida em diferentes componentes [12]: estrelas, gás atômico, gás quente ionizado e gás molecular, sendo que as duas últimas estão presentes em quantidades desprezíveis, mais o halo de matéria escura. Para deduzir a contribuição das componentes luminosas à velocidade de rotação, iguala-se a resultante centrípeta à força gravitacional, dessa vez sem assumir nenhuma hipótese a respeito da forma dessa força:

$$
-m \frac{v^{2}}{r} \overrightarrow{e_{r}}=m \vec{g} \Rightarrow-m \frac{v^{2}}{r} \overrightarrow{e_{r}}=-m \nabla \phi
$$

E assim chegamos a

$$
v^{2}=r \cdot \frac{\partial \phi}{\partial r} \Rightarrow v=\sqrt{r \cdot \frac{\partial \phi}{\partial r}}
$$

Então para determinar a contribuição de uma dada componente à velocidade é preciso conhecer o potencial gravitacional gerado por ela, que pode ser calculado conhecendo-se sua densidade de massa, através de uma "inversão" da equação de Poisson para o campo gravitacional $\left(\nabla^{2} \phi=4 \pi G \rho(r)\right)$ utilizando uma transformada de Hankel:

$$
\Phi(r, z)=-2 \pi G \int_{0}^{\infty} d k e^{-k|z|} J_{0}(k r) \int_{0}^{\infty} d r^{\prime} \Sigma\left(r^{\prime}\right) J_{0}\left(k r^{\prime}\right) r^{\prime},
$$

sendo $J_{0}$ a função de Bessel. Conhecendo-se a distribuição (ou densidade superficial) de massa $\Sigma(r)$ pode-se determinar o potencial, que é utilizado para calcular a contribuição dessa componente à velocidade de rotação.

As contribuições de cada componente da galáxia representam as curvas de rotação que seriam observadas caso houvesse apenas uma ou outra componente. Tendo em vista 
a equação A.1 e escrevendo o campo gravitacional total como a soma dos campos gerados pelas estrelas do disco $\overrightarrow{g_{d}}$, pelo gás $\overrightarrow{g_{g}}$ e pelo halo de matéria escura $\overrightarrow{g_{h}}, \vec{g}=\overrightarrow{g_{d}}+\overrightarrow{g_{g}}+\overrightarrow{g_{h}}$, percebe-se que a velocidade final é a soma quadrática dessas contribuições: $v^{2}=v_{d}^{2}+$ $v_{g}{ }^{2}+v_{h}{ }^{2}$. Assim é possível finalmente determinar a contribuição do halo de matéria escura à curva de rotação como $v_{h}{ }^{2}=v^{2}-v_{d}^{2}-v_{g}{ }^{2}$, onde $v$ é a velocidade de rotação observada. 


\section{Referências Bibliográficas}

[1] D. Larson et al, "Seven-Year Wilkinson Microwave Anisotropy Probe (WMAP) Observations: Power Spectra and WMAP-Derived Parameters", arXiv:1001.4635v1.

[2] A. Goldschmidt for the IceCube Collaboration, "The IceCube Detector", Proceedings of the 27th International Cosmic Ray Conference, Hamburg, Germany, 7-15 August 2001 (HE 2.5 19:36), 1237-1240.

[3] I. F. M. Albuquerque, C. P. Heros, "Closing the Window on Strongly Interacting Dark Matter with IceCube", arXiv:1001.1381v1.

[4] I. F.M. Albuquerque, L. Baudis, "Direct Detection Constraints on Superheavy Dark Matter", Physical Review Letters 90, 221301 (2003).

[5] G. D. Mack, J. F. Beacom, G. Bertone, "Towards closing the window on strongly interacting dark matter: Far-reaching constraints from Earth's heat flow", Phys. Rev. D 76, 043523 (2007).

[6] P. C. McGuire, P. J. Steinhardt, "Cracking Open the Window for Strongly Interacting Massive Particles as the Halo Dark Matter", Proceedings of the 27th International Cosmic Ray Conferences (ICRC 2001), Hamburg, Germany, Aug 2001. astro-ph/0105567.

[7] G. D. Starkman, A. Gould, R. Esmailzadeh, S. Dimopoulos, "Opening the window on strongly interacting dark matter", Phys. Rev. D 41, 3594 (1990).

[8] M. Blennow, J. Edsjo, T. Ohlsson, "Neutrinos from WIMP Annihilations Obtained Using a Full Three-Flavor Monte Carlo Approach", arXiv:0709.3898.

[9] F. Zwicky, "Die Rotverschiebung von extragalaktischen Nebeln", Helvetica Physica Acta 6, 110-127

[10] F. Zwicky, "On the Masses of Nebulae and of Clusters of Nebulae", Astrophysical Journal, vol. 86, p.217, http://adsabs.harvard.edu/cgi-bin/nph-bib_query? bibcode=1937ApJ . . . 86 . 217Z. 
[11] S. Smith, "The Mass of the Virgo Cluster", 1936, ApJ, 83, 23

[12] E. Corbelli , P. Salucci, "The extended rotation curve and the dark matter halo of M33", 2000, MNRAS, 311, 441.

[13] K. M. Ashman, "Dark Matter in Galaxies", PASP 140: 1109-1138, 1992.

[14] J.E. Carlstrom et al., "Imaging the Sunyaev-Zel'dovich Effect", astro-ph/9905255.

[15] B. S. Mason, S. T. Myers, "Mass Models and Sunyaev-Zeldovich Effect Predictions for a Flux Limited Sample of 22 Nearby X-Ray Clusters", astro-ph/9910438.

[16] D. Clowe et al., "A direct empirical proof of the existence of dark matter", 2006, ApJ, 648, L109.

[17] M. Markevitch, A. H. Gonzalez, L. David, A. Vikhlinin, S. Murray, W. Forman, C. Jones, W. Tucker1, "A TEXTBOOK EXAMPLE OF A BOW SHOCK IN THE MERGING GALAXY CLUSTER 1E 065756", ApJ 567:L27-L31, 2002

[18] D. Tytler, J. M. O’Meara, N. Suzuki, D. Lubin, "Review of Big Bang Nucleosynthesis and Primordial Abundances", astro-ph/0001318v1.

[19] A. Jenkins et al., "Evolution of structure in cold dark matter universes", astroph/9709010v2.

[20] C. Alcock et al. (MACHO Collaboration), Nature 365 (1993) 621.

[21] G. Jungman, M Kamionkowski, K. Griest, "Supersymetric Dark Matter", Physics Reports 267 (1996) 195-373.

[22] S. D. M. White, C. S. Frenk, M. Davis, "Clustering in a neutrino-dominated universe", ApJ 1983 274:L1-L5.

[23] K. Griest, M. Kamionkowski, "Unitarity limits on the mass and radius of dark-matter particles", Phys. Rev. Lett. 64, 615-618 (1990).

[24] D. J. H. Chung, E. W. Kolb, A. Riotto, "Nonthermal Supermassive Dark Matter", Physical Review Letters 81, 19.

[25] Y. Sofue1, M. Honma, T. Omodaka, "Unified Rotation Curve of the Galaxy Decomposition into de Vaucouleurs Bulge, Disk, Dark Halo, and the 9-kpc Rotation Dip —", arXiv:0811.0859v2.

[26] CDMS II Collaboration, "Dark Matter Search Results from the CDMS II Experiment", Science 327 (5973): 1619. 
[27] L. Hsu, "New Results from the Cryogenic Dark Matter Search", Joint ExperimentalTheoretical Physics Seminar, http://cdms.berkeley.edu/hsu_091217_FNAL.pdf.

[28] R. Bernabei, P. Belli, F. Cappella, R. Cerulli, F. Montecchia, F. Nozzoli, A. Incicchitti, D. Prosperi, C. J. Dai, H. H. Kuang, J. M. Ma, Z. P. Ye, "Dark Matter Search", astro-ph/0307403.

[29] R. Bernabei et. al., "Particle DarkMatter in the galactic halo: results from DAMA/LIBRA", AIP Conf. Proc. 1200 (2010), 993.

[30] E. Behnke et al, "Spin-Dependent WIMP Limits from a Bubble Chamber", Science 319, 933-936 (2008).

[31] J. Kopp, T. Schwetz, J. Zupan, "Global interpretation of direct Dark Matter searches after CDMS-II results", arXiv:0912.4264v3.

[32] A. Bottino, F. Donato, N. Fornengo, S. Scopel, "Relic neutralinos and the two dark matter candidate events of the CDMS II experiment", arXiv:0912.4025v1.

[33] C. Savage, K. Freese, P. Gondolo, D. Spolyar, "Compatibility of DAMA/LIBRA dark matter detection with other searches in light of new Galactic rotation velocity measurements", JCAP 0909:036,2009.

[34] D. Smith, N. Weiner, "Inelastic Dark Matter", Phys. Rev. D64:043502,2001

[35] J. Angle et al. (XENON), "First Results from the XENON10 Dark Matter Experiment at the Gran Sasso National Laboratory", Phys. Rev. Lett. 100, 021303 (2008).

[36] E. Aprile et al., "First Dark Matter Results from the XENON100 Experiment", arXiv:1005.0380v2.

[37] M. Boezio et al, "PAMELA and indirect dark matter searches", New J. Phys. 11 1050232009.

[38] O. Adriani et al, "An anomalous positron abundance in cosmic rays with energies 1.5-100 GeV", Nature 458, 607-609 (2009).

[39] A. A. Abdo et al, "Observations of MilkyWay Dwarf Spheroidal galaxies with the Fermi-LAT detector and constraints on Dark Matter models", arXiv:1001.4531v1.

[40] http://www.icecube.wisc.edu/news/

[41] A. Gould, "Resonant Enhancements in Weakly Interacting Massive Particle capture by the Sun", ApJ, 321:571-585, 1987. 
[42] http://www.icecube.wisc.edu/index.php.

[43] R. Abbasi et al (IceCube Collaboration), "Limits on a Muon Flux from Neutralino Annihilations in the Sun with the IceCube 22-String Detector", PRL 102, 201302 (2009).

[44] R. Abbasi et al (IceCube Collaboration), "Limits on a muon flux from Kaluza-Klein dark matter annihilations in the Sun from the IceCube 22-string detector", Physical Review D 81, 057101 (2010).

[45] R. Gandhi, C. Quigg, M. H. Reno, I. Sarcevic, "Neutrino interactions at ultrahigh energies", Physical Review D 58, 093009 (1998).

[46] S. Eidelman et al., "Particle Data Group - The Review of Particle Physics - Chapter 15: Neutrino mass, mixing, and flavor change", Physics Letters B 5922004.

[47] I. F. M. Albuquerque, L. Hui, E. W. Kolb, "High energy neutrinos from superheavy dark matter annihilation", Physical Review D 64, 083504.

[48] C. Hill, "Monopolonium”, Nucl. Phys. B224, 469 (1983).

[49] J.N. Bahcall, A.M. Serenelli, S. Basu, "New solar opacities, abundances, helioseismology, and neutrino fluxes", Astroph. J. 621, L85 (2005) [arXiv:astro-ph/0412440].

[50] W.F. McDonough, "Compositional Model for the Earth's Core", em "The Mantle and Core" (ed. R.W. Carlson.) Vol. 2, "Treatise on Geochemistry" (eds. H.D. Holland and K.K. Turekian), Elsevier-Pergamon, Oxford, 2003, pp. 547-568.

[51] W. A. Rolke, A M. López, J. Conrad, "Limits and confidence intervals in the presence of nuisance parameters", Nucl. Instrum. Meth. A551, 493-503 (2005).

[52] C. McCabe, "The Astrophysical Uncertainties Of Dark Matter Direct Detection Experiments", arXiv:1005.0579v1

[53] P. Salucci, F. Nesti, G. Gentile, C.F. Martins, "The dark matter density at the Sun's location", arXiv:1003.3101v1.

[54] M. Weber, W. de Boer (2009), "Determination of the Local Dark Matter Density in our Galaxy", arXiv:0910.4272.

[55] A. K. Drukier, K. Freese, D. N. Spergel, "Detecting cold dark-matter candidates", Physical Review D 333495 (1986).

[56] M. C. Smith et al., Mon. Not. Roy. Astron. Soc. 379, 755 (2007), astro-ph/0611671. 